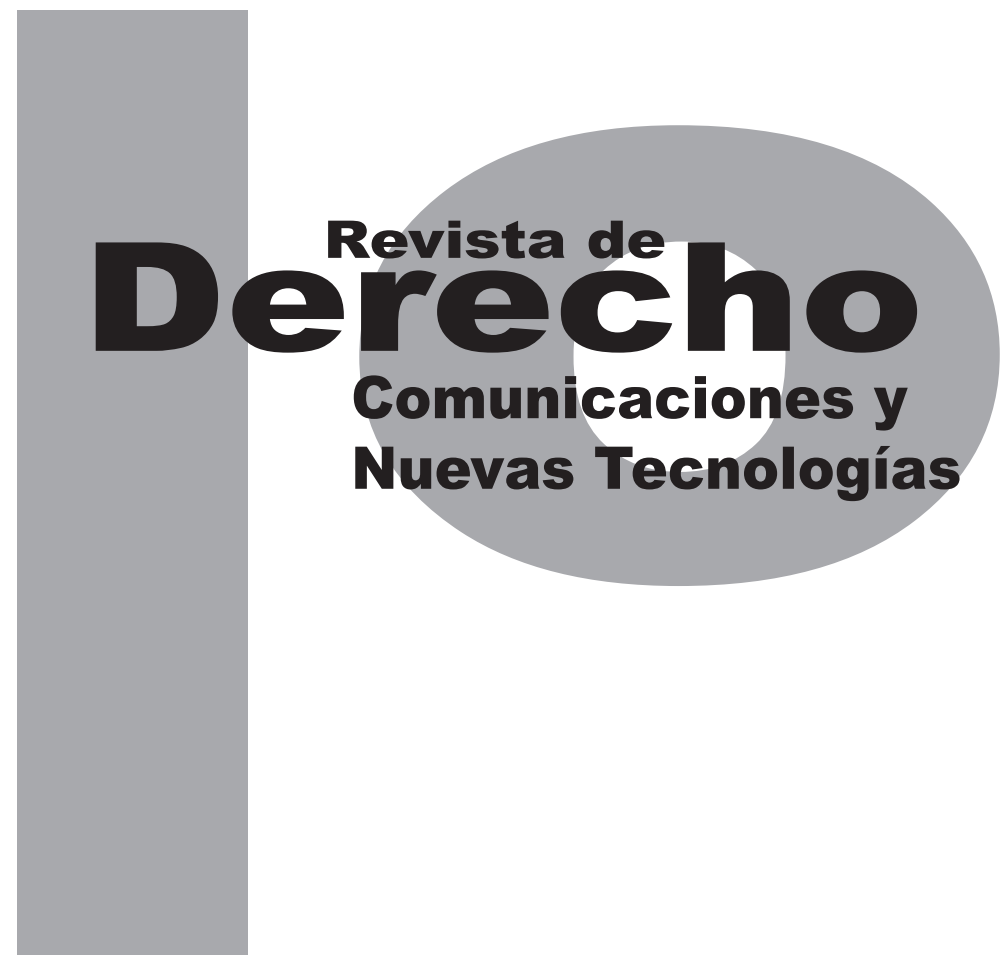

\title{
LA REVERSIÓN DEL PAGO DENTRO DEL CONTEXTO DEL COMERCIO ELECTRÓNICO Y SUS IMPLICACIONES PRÁCTICAS EN EL RÉGIMEN JURÍDICO COLOMBIANO
}

MARÍA LORENA FLóREZ ROJAS

Universidad de los Andes

Facultad de Derecho

Revista de Derecho, Comunicaciones y Nuevas Tecnologías

No. 10, Julio - Diciembre de 2013. ISSN 1909-7786 


\title{
La reversión del pago dentro del contexto del comercio electrónico y sus implicaciones prácticas en el régimen jurídico colombiano*
}

\author{
María Lorena Flórez Rojas ${ }^{* *}$
}

\begin{abstract}
RESUMEN
En una sociedad de consumo moderna, caracterizada por los constantes avances en tecnología, la normatividad interna de un país debe ir encaminada a eliminar las brechas digitales y materializar el derecho sin importar el medio usado, como lo es el comercio electrónico. A lo largo de este artículo se analiza la reversión de pago establecida por el Estatuto del Consumidor (L-1480/11). Se busca presentar en detalle el funcionamiento de la reversión del pago en contraste con el manejo que se le da en el actual mercado.
\end{abstract}

Palabras clave: derecho del consumo, Estatuto del Consumidor, comercio electrónico, ventas online, medios de pago electrónicos, plataformas de pago, reversión del pago, retracto, entidades financieras, proveedor y productor, devoluciones, casos prácticos.
In a modern consumer society characterized by the constant advances in technology, the internal regulations of any country should seek to remove the digital gaps and realize the law regardless of the medium used, in this case the e-commerce. Throughout this paper analyzes the reversal of payment established by the Statute of the Consumer (L-1480/11). It seeks to present in detail the operation of the reversal of payment in contrast to the handling that is given in the current market.

KEYWORDS: Consumer Law, General Statute Consumer, e-commerce, online sales, electronic payments, payment platforms, reversal of payment, redemption, financial institutions, supplier and producer, returns, case studies.

Cómo citar este artículo: Flórez Rojas, M. L. (Diciembre, 2013). La reversión del pago dentro del contexto del comercio electrónico y sus implicaciones prácticas en el régimen jurídico colombiano. Revista GECTI, 10

** Abogada de la Universidad de los Andes. Actualmente se desempeña como coordinadora de la Especialización en Derecho Comercial y del Grupo de Estudios en Internet, Comercio Electrónico, Telecomunicaciones e Informática (GECTI). Correo ml.florez66@uniandes.edu.co 


\section{SUMARIO}

Introducción - I. NATURALEZA Y EVOLUCIÓN DEL DERECHO DEL CONSUMO - A. Concepto y función del derecho del consumo - B. Evolución del derecho del consumo en Colombia - II. COMERCIO ELECTRÓNICO EN COLOMBIA - A. Medios electrónicos de pago - III. REVERSIÓN DE PAGO - A. Aplicación a bienes y servicios - B. Finalidad - C. Procedimiento - D. Términos y condiciones: casos prácticos - IV. CONCLUISONES - Bibliografía. 
Introducción

La sociedad de consumo moderna es caracterizada por los constantes avances en tecnología, que ponen de presente diferentes objetivos que se pretenden alcanzar como: (i) Exigir el suministro de información previa, clara, suficiente y completa para que el consumidor tome una decisión debidamente informada; (ii) Obligar al empresario a proveer bienes y servicios de calidad junto con la respectiva garantía; (iii) Proteger la información que el consumidor suministra con ocasión de una relación de consumo; y (iv) Ordenar la adopción de medidas de seguridad respecto de los medios de pago. Estos objetivos buscan proteger de forma eficaz al consumidor, como último eslabón de la cadena de producción.

Por ello, Colombia adoptó el Estatuto del Consumidor (L-1480/11), ${ }^{3}$ figura que constituye un avance respecto de la protección al consumidor $y$, en específico, en transacciones a través del comercio electrónico. Esta especial protección surge como respuesta al desequilibrio entre el consumidor y el proveedor o productor dentro de una relación de consumo.

Esta relación marcada de desigualdad entre consumidor y proveedor o productor se ve acentuada por las diferentes prácticas comerciales que tienen los empresarios para persuadir a los sujetos en el mercado. El objetivo de dichas prácticas es cautivar al consumidor, disminuyendo su capacidad de discernimiento. A pesar de que estas estrategias de mercado son lícitas,

3 Publicado en el Diario Oficial n. 48.220 del 12 de octubre de 2011. todavía se producen abusos de estos procedimientos, mecanismos o métodos con la consecuente vulneración de los derechos de los consumidores. Según cifras de la Superintendencia de Industria y Comercio (sIc), en Colombia durante el año 2010 se realizaron 3391 denuncias por publicidad engañosa, y en el año 2011 dicha cifra se incrementó a 3503, siendo los sectores con más denuncias la construcción, los cursos de idiomas, paquetes turísticos, servicios funerarios, venta de automotores y promociones e incentivos. ${ }^{4}$ Estas malas prácticas comerciales llevan a vulneraciones sistemáticas de los consumidores pues no afectan a un individuo en particular, sino en general a todo el grupo de consumidores.

\section{NATURALEZA Y EVOLUCIÓN DEL DERECHO DEL CONSUMO}

El derecho del consumo tiene sus raíces en la evolución de la sociedad de mercado, que cambia dependiendo de la oferta y demanda de bienes y servicios. Por lo tanto, y sin ánimo de realizar un detallado análisis histórico, es importante reseñar los grandes cambios en la sociedad en materia de mercado, para comprender el origen de la protección actual dentro de una relación de consumo.

Las primeras declaraciones de los derechos del hombre, la Bill of Rights británica de 1688 y la Declaración Francesa de los Derechos del Hom-

\footnotetext{
4 Entrevista realizada al doctor Alejandro Giraldo por la revista P\&M Publicidad \& Mercado. Colombia. Octubre 26 de 2011. Disponible en: http://www.revistapym.com.co/destacados/6-sectores-mas-denunciaspublicidad-enganosa-colombia
} 
bre y del Ciudadano de 1789, fueron los cimientos del capitalismo, ${ }^{5}$ pues la mayor parte de los derechos reconocidos en ellas han servido de fundamento para la nueva economía de mercado, debido a que consideraban a la libertad como derecho natural e imprescriptible, el cual fundamentaría el orden social, dando paso a la protección de la propiedad como derecho inviolable y sagrado. ${ }^{6}$

Este concepto de libertad fue evolucionando hasta consolidarse como núcleo dentro las relaciones entre particulares, a través de la libertad contractual ${ }^{7}$ plasmada en el Código de Napoleón de 1804. En este se establecía que "el contrato es ley para las partes", ${ }^{8}$ otorgando prioridad a la manifestación del individuo, como la exteriorización de su voluntad. Con ello se da comienzo a lo que se denominó Liberalismo Económico, ${ }^{9}$ en el cual crecía una sociedad de consumo basada en la teoría del libre mercado y el consumidor individual, en donde la relación entre consumidor y empresario se encontraban

5 BETANCUR, Belisario. Filosofía de los derechos humanos. En: Política y Derecho del Consumo. Bogotá, Colombia: Superintendencia de Industria y Comercio. Biblioteca Milenio, 1998, p. 25.

6 Artículo 17 de la Declaración Universal de los Derechos del Hombre y del Ciudadano.

7 HINESTROSA FORERO, Fernando. Tratado de las Obligaciones. 3ra. ed. Bogotá, Colombia: Universidad Externado de Colombia, 2007, p. 611

8 Artículo 1154 del Código de Napoleón.

9 Es la doctrina económica desarrollada durante la llustración, desde fines del siglo XVII hasta el inicio de la Revolución Francesa, formulada de forma completa en primer lugar por Adam Smith y David Ricardo, que reclama la mínima interferencia del Estado en la economía. Habitualmente se resume en la expresión francesa Laissez faire, Laissez passer (dejar hacer, dejar pasar), que no obstante es el lema de la fisiocracia, una teoría económica precedente. en igualdad de condiciones, pues su interacción se daba dentro de un mercado regido por la oferta y la demanda.

Como consecuencia, el concepto de libre competencia empezó a cobrar auge, pues cada empresario podía emplear sus recursos en la creación de un bien o servicio y cobrar por este una suma de dinero a su arbitrio. En este contexto, el mercado se autorregulaba y tenía poca intervención estatal; el consumidor era víctima de abusos por parte de los empresarios, como consecuencia tanto de una situación de inferioridad en el mercado como de disparidad en cuanto a los intereses de cada actor. ${ }^{10}$ Así, mientras los empresarios buscaban una mayor utilidad para sus bienes y servicios, los consumidores intentaban maximizar sus ingresos pagando menos por un bien, situación que se mantiene actualmente.

A partir de allí, el Estado consideró la necesidad de regular esta relación de consumo pues las interacciones de mercado ya no estaban siendo ejecutadas por dos partes en igualdad de condiciones. En respuesta a dicha necesidad se crearon figuras civiles como los vicios ocultos, la lesión enorme y mecanismos antimonopolios que alientan a la lealtad comercial, lo cual de forma indirecta beneficiaba al consumidor. En esta misma línea de protección, la Comisión Federal de Comercio $^{11}$ de los Estados Unidos de

10 VELANDIA, Mauricio. Derecho de la competencia y del consumo. 2da. ed. Bogotá, Colombia: Universidad Externado de Colombia, 2011, p. 57.

11 Federal Comision Trade es una agencia independiente del gobierno de los Estados Unidos, establecida en 1914 por la Federal Trade Co- 
Norteamérica reglamentó las prácticas comerciales desleales.

Dado que la forma cotidiana de la circulación de bienes y servicios de la época se efectuaba a través del modelo de contratación persona a persona, este se hizo obsoleto y dio lugar a la figura de contratos preestablecidos, en los cuales se sustituyeron los acuerdos entre comprador y vendedor por cláusulas preestablecidas por parte del contratante más fuerte. Del mismo modo, los medios tradicionales de resolución de contratos se hicieron inoperantes, ya que sus costos superaban muchas veces el valor del bien o servicio que se reclamaba. A su vez, el conjunto de personas que estaban siendo afectadas por este tipo de relación contractual no gozaban de un régimen especial que los distinguiera de los demás grupos de consumidores.

El Tratado de Roma de 1957 crea la Comunidad Europea, ${ }^{12}$ y en sus artículos 85 y 86 establece las bases para la sana competencia en el mercado y para evitar las prácticas comerciales desleales. Además, la Resolución 543 del 14 de abril de 1975, del Consejo de la Comunidad Europea, aprobó el programa preliminar de la Comunidad Económica Europea (CEE) para una

mision Act. Su principal misión es la promoción de la protección al consumidor y la eliminación y prevención de prácticas anticompetitivas.

12 Este Tratado tiene por objetivo la integración a través de los intercambios con fines de expansión económica. A partir del Tratado de Maastricht, la CEE se convierte en la Comunidad Europea, lo que expresa la voluntad de los Estados miembros de ampliar las competencias comunitarias a ámbitos no económicos. El Tratado CEE prevé la creación de un mercado común, de una unión aduanera y de políticas comunes. Los artículos 2 y 3 del Tratado abordan directamente estos tres temas. Precisan. Tomado de: http://europa.eu/legislation_summaries/institutional_affairs/treaties/treaties_eec_es.htm Consultado el día 13 de febrero de 2013 política de protección e información de los consumidores. En esta carta se reconocieron cinco derechos fundamentales de los consumidores, a saber: i) Derecho a la protección de su salud y su integridad; ii) Derecho a la protección de intereses económicos; iii) Derecho a la reparación del daño por la circulación de productos defectuosos o la difusión de mensajes engañosos o erróneos; ${ }^{13}$ iv) Derecho de información sobre las calidades del producto y del proveedor, y educación; ${ }^{14}$ y v) Derecho de los consumidores a organizarse en asociaciones y ser representados por diversos organismos. ${ }^{15}$ Esta Resolución sería el modelo para los ordenamientos de los países miembros de la $\mathrm{CEE}^{16} \mathrm{y}$ de otros no pertenecientes a dicha Comunidad.

Con estas bases establecidas, el 9 de abril de 1985 la Asamblea General de la onu aprobó un documento con las directrices para la protección al consumidor, ${ }^{17}$ en las que reconoce la especial situación de los consumidores con relación a los empresarios, concretamente un desequilibrio respecto de la capacidad econó-

13 Derecho a recibir productos de calidad, a la seguridad e indemnidad, a recibir protección en contra de la publicidad engañosa, establecidos en el art. 3 numerales 1.1, 1.2 y 1.4, respectivamente, de la Ley 1480 de 2011

14 Derecho a recibir información, a informar, a la educación, establecidos en el art. 3 numerales $1.3,1.10$ y 1.11 , respectivamente, de la Ley 1480 de 2011.

15 Derecho a la participación y a la representación, establecidos en el art. 3 numerales 1.8 y 1.9, respectivamente, de la Ley 1480 de 2011.

16 Por ejemplo, la Market Practice Act de 1970, en Suecia.

17 Directrices de las Naciones Unidas para la protección al consumidor, 9 de abril de 1985. Departamento de Asuntos Económicos y Sociales. [En línea]. Disponible en: http://es.consumersinternational.org/media/888028/directrices\%20onu_sp.pdf. Consultado el 20 de febrero de 2013. 
mica, el nivel de educación y el poder de negociación. Estas consideraciones jurídicas deberían ser tenidas en cuenta por los países miembros para la estructuración y fortalecimiento de sus ordenamientos internos. Con base en estos documentos, la definición de objetivos generales en diferentes aspectos aumentó hasta consolidarse todo un marco jurídico respecto a la protección al consumidor. ${ }^{18}$

Este derecho nos vincula a todos como consumidores y la protección como tales es entonces de interés general, tal y como lo expuso el presidente Kennedy: "Consumidores, lo somos todos. Si el consumidor no tiene oportunidad de elegir en base a una adecuada información, se despilfarra su dinero y su salud y seguridad quedan amenazadas, con lo que en el fondo, lo que sufre es el interés nacional". ${ }^{19}$ Es así como los derechos de los consumidores no solo merecen una especial protección, sino que son catalogados como derechos económicos, sociales y culturale ${ }^{20}$ dentro de los derechos humanos, ${ }^{21}$

18 Resolución del Consejo, de 19 de mayo de 1981, sobre un segundo programa de la Comunidad Económica Europea para una política de protección y de información de los consumidores. Directiva 79/581/ CEE relativa a los principios de determinados productos alimenticios. Directiva 88/314/CEE relativa a los productos no alimenticios. Directiva 85/374/CEE relativa a la responsabilidad de productos defectuosos. Directiva 98/6/CE relativa a la protección de los consumidores en materia de indicación de los precios de los productos ofrecidos a los consumidores, entre documentos locales e internacionales.

19 ESCAJEDO SAN EPIFANIO, Leire. La base jurídico-constitucional de la protección de los consumidores en la Unión Europea. En: Revista de Derecho Político. 2007. vol. 70, p. 254.

20 Pacto Internacional de los Derechos Económicos, Sociales y Culturales, del 16 de diciembre de 1966. Véase también en: http://www. derechoshumanos.net/derechos/index.htm?gclid=CJmh9sjkmrYCFYd IOgodBx0Abg. Consultado el día 24 de febrero de 2013.

21 Véase también en GHERSI, Carlos Alberto. La concepción filosófica del derecho del consumo y su relación con otras disciplinas. En: Polí- debido a que son considerados como el "vehículo social de protección general, vinculado a derechos elementales de la persona humana, encuadrado dentro del marco de lo que llamamos derechos humanos". 22

\section{A. Concepto y función del derecho del consumo}

El concepto de consumo hace referencia como primera medida a la fabricación o producción en serie de bienes o servicios, evidente desde la Revolución Industrial hasta la inducción publicitaria como herramienta de mercado y a la satisfacción de necesidades particulares. En pocas palabras, el concepto de consumo es el resultado de una cadena de producción de bienes y servicios condicionada a una serie de necesidades sociales que se termina manifestando en una situación de dominación. ${ }^{23}$

Esta situación de asimetría ${ }^{24}$ se deriva del liberalismo conservador, según el cual los "perdedores" del sistema de la libre competencia deben ser protegidos por el Estado, debido a que dentro de este régimen los usuarios buscan satisfacer sus necesidades a través de los bienes o servicios ofrecidos por aquellos que los poseen, sometiendo al usuario a la imposición

tica y derecho del consumo. Bogotá, Colombia: Superintendencia de Industria y Comercio. Biblioteca Milenio. 1998, p. 39-47.

22 TAMBUSSI, Carlos Eduardo. El consumo como derecho humano. Buenos Aires, Argentina: Universidad, 2009, p. 222.

23 GHERSI, Carlos Alberto. Óp. cit., p. 39-47.

24 BURGOS PUYO, Andrea. El consumidor y los contratos en Internet. Bogotá, Colombia: Universidad Externado de Colombia, 2007, p. 67. 
de condiciones. ${ }^{25}$ En varias ocasiones, el consumidor se acerca al mercado no para buscar la satisfacción de una necesidad específica, sino porque el mercado a través de la publicidad le genera una serie de necesidades inexistentes y le hace creer que determinado producto suplirá una necesidad que ni tenía ni la había contemplado. ${ }^{26}$ Estos casos en los cuales el consumidor es atraído hacia el mercado, bien por lograr un estatus particular, por obtener premios asociados a un bien o servicio o porque está en una situación cautiva, son los que llevan a determinar que este no se encuentra en una relación de iguales frente a la otra parte contratante.

Mientras que en un contrato bilateral una de las partes envía una oferta a la otra para que esta la modifique, la acepte o la rechace en el marco de un ambiente de negociación y razonamiento sobre cada elemento del contrato, en las relaciones de consumo el campo de negociación es casi nulo, pues la oferta por lo general viene incluida dentro de la publicidad, que a su vez contiene elementos subjetivos que eliminan de cierto modo la capacidad de discernir del consumidor. Por lo anterior, las relaciones de consumo se basan en una negociación de confianza, ya que la discusión sobre los elementos del contrato resulta ser prácticamente inexistente. ${ }^{27}$

El derecho del consumo hace referencia, entonces, al "conjunto de reglas aplicables a los actos

\footnotetext{
25 TAMBUSSI, Carlos Eduardo. Óp. cit., p. 225.

26 LORENZETTI, Ricardo Luis. Consumidores. Buenos Aires, Argentina: Rubinzal-Culzoni, 2003, p. 566.

27 lbíd., p. 570.
}

de consumo, o lo que resulta lo mismo, a las relaciones entre profesionales y consumidores" ${ }^{28}$ Dentro de una relación de consumo la parte más vulnerable será la del consumidor y, por ende, será la protegida por el Estado. Este concepto de consumidor como parte frágil dentro de la relación de consumo se puede asemejar, pero no equiparar, al concepto de trabajador como parte débil dentro de una relación laboral, pues los consumidores son una masa heterogénea y diseminada con diferentes problemáticas, y muchas veces con pocas conexiones, a diferencia de los trabajadores quienes sí hacen parte de un grupo determinado. ${ }^{29}$ El principio jurídico sobre el cual se construye la protección a los consumidores será entonces el de favor debilis, ${ }^{30}$ el cual se enfoca en proteger a la parte débil dentro de una relación.

La producción en masa de los diversos bienes y servicios, la adhesión o aceptación a predisposiciones impuestas por el empresario, los avances en materia tecnológica, el auge del consumo transfronterizo y el impacto de la publicidad en el consumidor son algunas de las causas que llevaron a la creación del derecho del consumo. Dentro de este derecho se pueden establecer tres fines que buscan contrarrestar dichas causas, a saber: a) Un fin de reparación contra las deformaciones que el medio comercial y económico hace sufrir a la libertad contractual, b) Un

28 CALAIS-AULOY, Jean. Droit de la Consommation. 8 ed. Paris, Francia: Dalloz, 2010, p.744. Universidad Santo Tomás. Grupo Editorial Ibañez, 2013, p. 780. 
fin preventivo tendiente a evitar las prácticas lesivas y c) Un fin educativo para convertir al consumidor en parte activa de la relación. ${ }^{31}$

\section{B. Evolución del derecho del consumo en Colombia}

La relación asimétrica entre consumidor y proveedor o distribuidor ha sido analizada por la Corte Constitucional, ${ }^{32}$ en atención a que la Carta Política de 1991 ordena la existencia de un campo de protección en favor del consumidor, "inspirado en el propósito de restablecer su igualdad frente a los productores y distribuidores, dada la asimetría real en que se desenvuelve la persona que acude al mercado en pos de la satisfacción de sus necesidades humanas". ${ }^{33}$ Así, la regulación dirigida a salvaguardar los derechos de los consumidores pretende equiparar las partes de una relación de consumo, debido a "las hondas desigualdades inmanentes al mercado y al consumo". ${ }^{34}$

La Corte expuso que esta relación desigual se debe, en primer lugar, al avance de la ciencia y la tecnología, ${ }^{35}$ pues dada la especialización

31 TAMBUSSI, Carlos Eduardo. Óp. cit., p. 246.

32 CORTE CONSTITUCIONAL. Sentencia C-1141 de agosto 30 de 2000. Referencia: expediente D-2830. Magistrado ponente: Eduardo Cifuentes Muñoz. Corte Constitucional, sentencia C-749 de 2009. Referencia: expediente D-7686. Magistrado ponente: Luis Ernesto Vargas Silva.

33 CORTE CONSTITUCIONAL. Sentencia C-1141 de agosto 30 de 2000. Referencia: expediente D-2830. Magistrado ponente: Eduardo Cifuentes Muñoz.

34 CORTE CONSTITUCIONAL. Sentencia C-749 de 2009. Referencia: expediente D-7686. Magistrado ponente: Luis Ernesto Vargas Silva.

35 Ibíd. de los procesos productivos surge una asimetría de información entre los sujetos que concurren al mercado. En efecto, los consumidores suelen carecer de conocimiento y experticia suficientes para discernir acerca de los aspectos técnicos de los bienes y servicios que están en el mercado, y por lo tanto primará una negociación de confianza. En segundo lugar, en esta relación asimétrica se evidencia la magnitud empresarial de los fabricantes y comercializadores, ${ }^{36}$ puesto que son ellos quienes cuentan con determinada infraestructura administrativa y recursos económicos que crean ventajas frente al manejo de resolución de conflictos, asesorías profesionales, entre otras.

De otro lado, la Corte Constitucional se ha pronunciado sobre el derecho colectivo de los consumidores, otorgándole un estatus de derecho poliédrico en virtud de que "Ios derechos del consumidor, no se agotan en la legítima pretensión a obtener en el mercado, de los productores y distribuidores, bienes y servicios que reúnan unos requisitos mínimos de calidad y aptitud para satisfacer sus necesidades", ${ }^{37}$ sino que, por el contrario, incorpora pretensiones, intereses y situaciones de orden sustancial, tales como la calidad de bienes y servicios; de orden procesal como la exigibilidad judicial de las garantías, la indemnización de perjuicios y las diferentes acciones en contra de productores y proveedores; $y$ de orden participativo frente a la

$36 \quad$ Ibíd.

37 CORTE CONSTITUCIONAL. Sentencia C-1141 de agosto 30 de 2000. Referencia: expediente D-2830. Magistrado ponente: Eduardo Cifuentes Muñoz. 
administración pública y a los órganos reguladores para lograr una íntegra protección.

Durante el proceso que realizó la Constituyente podemos observar que, a pesar de ser un tema de alta relevancia, fue tratado desde la órbita de la libre competencia y de la prohibición de constituir monopolios que afectarían a los consumidores. Así, en el Proyecto de Acto Reformatorio de la Constitución Política de Colombia $n .^{\circ}$ $59^{38}$ se realizó un análisis acerca del régimen económico y servicios públicos, y se estableció que el derecho a la libre competencia económica va más allá de la competencia equitativa y leal, pues "constituye a su vez un derecho colectivo esencial de los consumidores y usuarios de bienes y servicios, por cuanto de no existir la competencia económica estarían sometidos al ejercicio del poder monopólico o al abuso de la posición dominante". 39

La Corte, a su vez, plantea que la consagración de derecho colectivo no resulta fácil, pues la titularidad del derecho siempre implica un sujeto de derecho, que para este caso sería la colectividad. Dado que la colectividad no goza de personería jurídica, la ley establece que estos derechos están en cabeza de todos los individuos que pertenecen a un determinado grupo humano o social, y así el goce efectivo del derecho responde a las necesidades de este grupo. Por lo tanto, en caso de ser desconocidos se produ-

38 Gaceta Constitucional n. ${ }^{\circ}$ 22. Proyecto de Acto Reformatorio de la Constitución Política n. ${ }^{\circ}$ 59, p. 206. Consultado el 15 de abril de 2013. Disponible en: http://www.elabedul.net/Documentos/Temas/Asamblea_Constituyente/Gaceta_022.pdf

39 Ibíd., p. 211. ciría un daño colectivo y social, es decir, que el daño se presenta de forma idéntica y homogénea en varias personas.

Teniendo en cuenta el avance histórico en materia económica y legislativa referente al derecho del consumo, resulta importante señalar los avances a nivel nacional en la materia para comprender las bases de la figura de la reversión. La primera aproximación a la protección de los derechos del consumidor se estableció en la Ley 73 de $1981^{40}$ y en los decretos $3466^{41}$ y $1441,{ }^{42}$ ambos de 1982, los cuales reglamentaron la ley en mención. Durante casi treinta años Colombia tuvo como eje para la protección al consumidor dichas normas, las cuales crearon las bases para regular la asimetría en la relación de consumo. Sin embargo, hasta la expedición de la Constitución de 1991 se le otorgó el carácter de derecho colectivo a los derechos de los consumidores.

Al respecto de estos derechos se propuso una redacción ${ }^{43}$ de la siguiente forma: "Artículo 5. Derechos de los consumidores. El Estado garan-

40 Por la cual el Estado interviene en la Distribución de Bienes y Servicios para la Defensa del Consumidor, y se conceden unas Facultades Extraordinarias. Diario Oficial n. ${ }^{\circ} 35.904$ de 15 de diciembre de 1981.

41 Reglamentado parcialmente por los decretos nacionales 863 de 1988, 1490 de 1993, 1485 de 1996 y 147 de 1999, por el cual se dictan normas relativas a la idoneidad, la calidad, las garantías, las marcas, las leyendas, las propagandas y la fijación pública de precios de bienes y servicios, la responsabilidad de sus productores, expendedores y proveedores, y se dictan otras disposiciones.

42 Decreto 1441 de mayo 24 de 1982 "Por el cual se regula la organización, el reconocimiento y el régimen de control y vigilancia de las ligas y asociaciones de consumidores y se dictan otras disposiciones. Diario Oficial n. ${ }^{\circ} 36.024$, de 11 de junio de 1982.

43 Redacción propuesta por la Confederación Colombiana de Consumidores. 
tizará a los consumidores y usuarios derechos de representación, protección, información, indemnización y otros similares que aseguren un adecuado equilibrio en las relaciones económicas de la sociedad." Con ello se buscaba que los derechos de los consumidores pudieran ser salvaguardados por el Estado, sin embargo, es claro cómo la enunciación de algunos derechos y la amplitud de otros, no permite establecer de forma precisa los derechos que los consumidores tienen frente a los productores y a los proveedores.

Por otro lado, la Constituyente estableció que los derechos colectivos debían gozar de algún mecanismo de protección especial y para su salvaguarda elevó a rango constitucional las acciones populares y de grupo. Y como elemento nuevo estableció el daño colectivo y su correspondiente indemnización. Además, determinó que dicha acción podrá ser usada "cuando los productos, bienes o servicios que adquieran adolezcan de calidad o de cantidad suficiente". ${ }^{44}$ Al finalizar el proceso, en la Constituyente quedaron los artículos 13 y 78. En el primero de ellos se establece que el Estado deberá promover las condiciones para que la igualdad sea real y efectiva, y adoptar las medidas necesarias para proteger los grupos discriminados o marginados, dentro de los cuales se encuentran los consumidores. ${ }^{45}$
Por su parte, el artículo 78 establece que será la ley quien regule el control de calidad de bienes ofrecidos y presentados a la comunidad, de manera que serán responsables quienes en la producción y en la comercialización de bienes y servicios atenten contra la salud, la seguridad y el adecuado aprovisionamiento a consumidores y usuarios. Resulta lamentable que la Carta Política no haya establecido los parámetros necesarios para una debida protección al consumidor, lo que permitió que estos lineamientos fueran desarrollados a través de la jurisprudencia, los decretos reglamentarios y, en esencia, los contratos.

A pesar de la necesidad imperiosa de regular la materia y de estar acorde con los avances internacionales, Colombia no dispuso oportunamente de una nueva normatividad, lo que produjo que el mercado, la competencia y las nuevas tecnologías se desarrollaran sin la protección adecuada para el último eslabón de la cadena de producción: el consumidor. Sin embargo, surgieron algunas propuestas legislativas que nunca se consolidaron como leyes de la República por tránsito de legislatura. Estos proyectos se presentan en el cuadro 1.

44 Gaceta Constitucional n. ${ }^{\circ}$ 22. Óp. cit., p. 262.

45 Frente a este punto, la Corte Suprema de Justicia en la sentencia de casación del 30 de abril de 2009 estableció que el Constituyente lo que buscaba con el artículo 13 era "la efectividad material del derecho a la igualdad, imponiéndose, entonces, que para tal fin se trate de manera distinta a personas ubicadas en situaciones diferentes, como sucede con el productor y el consumidor, pues este por la posición en la que se encuentra frente al otro demanda una especial protección de sus derechos, en la medida que es la parte débil de la relación de consumo". 


\section{Cuadro 1. Comparación ${ }^{46}$ Proyectos de Ley en Co- lombia en materia de defensa del consumidor.}

\begin{tabular}{|c|c|c|}
\hline 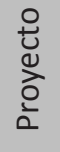 & $\begin{array}{c}\text { Proyecto de Ley } 115 \text { del } 14 \text { de noviembre de } 2000 . \\
\text { Cámara. Por el cual se expide el Estatuto de De- } \\
\text { fensa del Consumidor }\end{array}$ & $\begin{array}{c}\text { Proyecto de Ley } 82 \text { de } 2008 \text {. Senado. Por medio del } \\
\text { cual se actualiza el Decreto } 3466 \text { de } 1982 \text { y se dic- } \\
\text { tan otras disposiciones }{ }^{47}\end{array}$ \\
\hline$\frac{P}{\frac{0}{0}}$ & $\begin{array}{l}\text { Proteger, promover y garantizar la efectividad y el } \\
\text { libre ejercicio de los derechos de los consumidores, } \\
\text { así como amparar el respeto a su dignidad y a sus } \\
\text { intereses económicos. }\end{array}$ & $\begin{array}{l}\text { Regular los derechos y las obligaciones surgidas en- } \\
\text { tre los productores, proveedores y consumidores y } \\
\text { la responsabilidad de los productores y proveedores, } \\
\text { tanto sustancial como procesalmente. }\end{array}$ \\
\hline 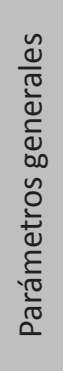 & $\begin{array}{l}\text { - Regular los derechos y las obligaciones surgidas } \\
\text { en las relaciones de consumo, } \\
\text { - Los contratos de adhesión, } \\
\text { - Las cláusulas abusivas, } \\
\text { - La responsabilidad por productos defectuosos y } \\
\text { - El funcionamiento de las organizaciones de con- } \\
\text { sumidores. }\end{array}$ & $\begin{array}{l}\text { - Regular los derechos y las obligaciones surgidas } \\
\text { con ocasión de las relaciones de consumo, } \\
\text { - Los contratos de adhesión, } \\
\text { - Las cláusulas abusivas, } \\
\text { - La responsabilidad por productos defectuosos y } \\
\text { - El funcionamiento de las organizaciones de con- } \\
\text { sumidores. }\end{array}$ \\
\hline 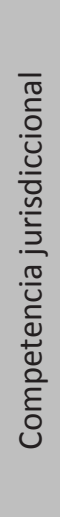 & $\begin{array}{l}\text { Los jueces civiles del circuito o municipales, por } \\
\text { razón de la cuantía, serán competentes para con- } \\
\text { ocer de las acciones para declarar: } \\
\checkmark \text { El incumplimiento de cualquiera de las ga- } \\
\text { rantías y obligaciones } \\
\checkmark \text { La responsabilidad solidaria de productores } \\
\checkmark \text { Resolver en todos los casos sobre la indemni- } \\
\text { zación de perjuicios. } \\
\text { Esta acción se tramitará por medio del proceso ver- } \\
\text { bal sumario (artículos 43-48). }\end{array}$ & $\begin{array}{l}\text { Las Alcaldías conocerán a prevención junto con los } \\
\text { jueces de la República de las acciones especiales } \\
\text { del consumidor. Los jueces del circuito y los jueces } \\
\text { municipales conocerán en razón de la cuantía. La Su- } \\
\text { perintendencia de Industria y Comercio conocerá en } \\
\text { segunda instancia de los recursos de apelación y del } \\
\text { recurso de súplica en todos los casos decididos por } \\
\text { los Alcaldes y sin sujeción a la cuantía (artículos 49- } \\
\text { 59). }\end{array}$ \\
\hline
\end{tabular}

46 Publicado en la Gaceta 450/00. Ponencia para primer debate en la Gaceta 211/01. Aprobación en primer debate en la Gaceta 523/02. Ponencia segundo debate en la Gaceta 73/02. Aprobación en segundo debate en la Gaceta 269/02.

47 Publicado en la Gaceta 502/08. Ponencia para primer debate en la Gaceta 602/08. Aprobación en primer debate en la Gaceta 808/08. Ponencia segundo debate en la Gaceta 165/09. Aprobación en segundo debate en la Gaceta 314/09. Ponencia Tercer debate en la Gaceta 927/09. Publicación cuarto debate 228/10. 


\begin{tabular}{|c|c|c|}
\hline 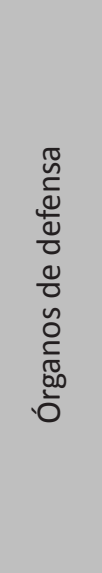 & $\begin{array}{l}\text { Las superintendencias de Industria y Comercio, Ban- } \\
\text { caria, de Servicios Públicos Domiciliarios, Vigilancia } \\
\text { Privada, de Subsidio Familiar, Nacional de Salud y el } \\
\text { Invima velarán por el cumplimiento de las normas } \\
\text { contenidas en esta ley. } \\
\text { La autoridad competente será aquella a la que le } \\
\text { corresponda vigilar o controlar al proveedor o las } \\
\text { actividades que desarrolla y lo no cubierto se en- } \\
\text { tenderá responsabilidad de la Superintendencia de } \\
\text { Industria y Comercio. (Artículo 52). }\end{array}$ & $\begin{array}{l}\text { La Superintendencia de Industria y Comercio tiene } \\
\text { ciertas facultades: } \\
\text { - Revisar los contratos de adhesión. } \\
\text { - Establecer la información que deba indicarse en } \\
\text { determinados productos. } \\
\text { - Adelantar las investigaciones. } \\
\text { - Practicar visitas de inspección. } \\
\text { - Solicitar la intervención de la fuerza pública en } \\
\text { caso de renuencia. } \\
\text { - Difundir el conocimiento de las normas sobre pro- } \\
\text { tección al consumidor. }\end{array}$ \\
\hline 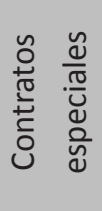 & $\begin{array}{l}\text { En los contratos celebrados a distancia, telefónica- } \\
\text { mente, por medios electrónicos o similares, el pro- } \\
\text { ductor deberá dejar constancia de la aceptación del } \\
\text { adherente a las condiciones generales. (Artículo 42). }\end{array}$ & $\begin{array}{l}\text { En los contratos celebrados a distancia, telefónica- } \\
\text { mente, por medios electrónicos o similares, el pro- } \\
\text { ductor deberá dejar prueba de la aceptación del ad- } \\
\text { herente a las condiciones generales. (Artículo 47). }\end{array}$ \\
\hline 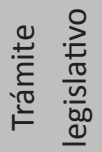 & $\begin{array}{l}\text { El proyecto fue archivado por tránsito de legislatura } \\
\text { según el art. } 190 \text { de la Ley } 5 \text { de } 1992 .\end{array}$ & $\begin{array}{l}\text { El proyecto fue archivado por tránsito de legislatura } \\
\text { según el art. } 190 \text { de la Ley } 5 \text { de } 1992 .\end{array}$ \\
\hline
\end{tabular}

Fuente: elaboración propia.

Cabe resaltar entonces, que a pesar de que los dos proyectos debatidos en el Congreso muestran un gran avance frente al Decreto 3466 de 1982, ninguno de los dos contiene obligaciones o deberes frente a los contratos celebrados a través de medios electrónicos y los dejan a discreción del proveedor o distribuidor, pues la única obligación que recae sobre ellos es la prueba sobre la existencia de la relación de consumo.

Desde el año 1982 y hasta el 2011 fueron las Altas Cortes y la Superintendencia de Industria y Comercio, a través de la jurisprudencia, conceptos y circulares, quienes de una u otra forma modularon los derechos de los consumidores.
Por ejemplo, la Corte Constitucional se ha pronunciado sobre temas como la propaganda comercial, la información y la publicidad engañosa, señalando que las ofertas, propagandas y promociones se incorporan al contrato y obligan a la empresa en su integridad, y que el productor y el proveedor son responsables por la información distribuida en el mercado. ${ }^{48}$ También, afirma que los productores y comercializadores de bienes y servicios son responsables de la calidad e idoneidad de sus productos, que estos no pueden afectar la salud de los consu-

48 CORTE CONSTITUCIONAL. Sentencia T-118 de 2000. Referencia. Expediente: T-250298. Magistrado ponente: José Gregorio Hernández Galindo; Sentencia T-747 de 2002. Referencia. Expediente: T-599615. Magistrado ponente: Marco Gerardo Monroy Cabra; Sentencia T-145 de 2004. Referencia. Expediente: T-730843. Magistrado ponente: Álvaro Táfur Galvis. 
midores y, por tanto, debe existir un deber de información acerca de su composición, riesgos y prevenciones. ${ }^{49}$

Por otro lado, la Corte Suprema de Justicia ha mencionado que la relación de consumo, entendida esta como una correspondencia entre desiguales, "traspasa las relaciones tradicionales propias del derecho privado, para extenderse a las que se ajustan entre el Estado y los diversos actores del mercado, en la medida en que tengan injerencia en los intereses de la colectividad". ${ }^{50}$ Será este entonces un especial campo de protección no solo por la marcada diferencia entre las partes que conforman la relación de consumo, sino porque la violación a los derechos de los consumidores afecta a la sociedad en general. De igual forma, establece que el distribuidor será responsable por las fallas en los bienes o servicios que distribuya pero hasta la garantía mínima presunta, sin que esto excluya del proceso al productor, ${ }^{51}$ así como la responsabilidad precontractual en lo concerniente a la propaganda comercial engañosa. ${ }^{52}$

49 CORTE CONSTITUCIONAL. Sala Plena. Sentencia C-973 de 2002. Referencia. Expediente: D-4032. Magistrado ponente: Álvaro Tafur Galvis; Sala Tercera de Revisión. Sentencia T- 333 de 2000. Referencia. Expediente: T-267601. Magistrado ponente: Eduardo Cifuentes Muñoz.

50 CORTE SUPREMA DE JUSTICIA. Sala de Casación Civil. Sentencia del 3 de mayo de 2005. Referencia. Expediente: 500013103001199904421-01. Magistrado ponente: César Julio Valencia Copete.

51 CORTE SUPREMA DE JUSTICIA. Sala Plena. Sentencia 107 de 1986. Referencia. Expediente: 1496. Magistrado ponente: Hernando Gómez Otálora.

52 CORTE SUPREMA DE JUSTICIA. Sala de Casación Civil. Sentencia del 13 de diciembre de 2001. Referencia. Expediente: 6775. Magistrado ponente: Manuel Ardila Velásquez.
El Consejo de Estado también se ha pronunciado sobre algunos aspectos relativos al consumidor. Por ejemplo, en lo atinente a la publicidad y propaganda comercial, afirmó en su momento la responsabilidad por inducción a error en la prestación de servicios de hospedaje ofrecidos en Colombia y prestados en el exterior, por carecer esta de idoneidad, calidad y naturaleza. ${ }^{53} \mathrm{~A}$ su vez, que la información no veraz e insuficiente frente a la propaganda con incentivos genera responsabilidad y sanciones pecuniarias. ${ }^{54}$

Por su parte, la Superintendencia de Industria y Comercio estableció que la relación de consumo se caracteriza por una operación en la cual media una parte que no posee conocimientos técnicos, cuyos intereses deberán protegerse de forma especial. ${ }^{55}$ Determinó también que el concepto o definición de consumidor estaba dado por la finalidad de la operación realizada, pues en los casos en los cuales el adquirente vuelve a colocar el bien en el mercado sin consumirlo, este no se regirá por la normativa de consumidor sino, por el contrario, deberá acceder a la vía jurisdiccional y se entenderá su calidad como la de proveedor. ${ }^{56}$ Adicionalmente, da-

53 CONSEJO DE ESTADO. Sala de lo Contencioso Administrativo. Sección Primera. Sentencia del 24 de septiembre de 1998. Referencia. Expediente: 5014. Consejero ponente: Juan Alberto Polo Figueroa.

54 CONSEJO DE ESTADO. Sala de lo Contencioso Administrativo. Sección Primera. Sentencia del 8 de mayo de 2003. Referencia. Expediente: 25000-23-24-000-2001-0849-01(8149). Consejero ponente: Manuel Santiago Urueta Ayola.

55 SUPERINTENDENCIA DE INDUSTRIA Y COMERCIO. Conceptos n. ${ }^{\circ}$ 960272 del 2 de septiembre de 1996, 96060904 del 28 de noviembre de 1996, 15125 del 23 de mayo de 2000, 010668522 del 28 de agosto de 2001.

SUPERINTENDENCIA DE INDUSTRIA Y COMERCIO. Concepto n. ${ }^{\circ}$ 97023655 del 17 de julio de 1997. 
das las facultades jurisdiccionales que le fueron otorgadas, expidió la Circular Única ${ }^{57}$ que en su Título II compila la regulación sobre protección al consumidor; en ella establece las características técnicas y detalladas sobre aspectos como la calidad e idoneidad de bienes y servicios, la información, la publicidad, la adquisición de bienes por medios de financiación, entre otros. ${ }^{58}$ A través de esta Circular, la Superintendencia pretende modular y especificar conceptos sobre temas relacionados con el consumidor y crear un marco de aplicación que le servirá de guía tanto a los consumidores como a proveedores y productores.

El Ministerio de Industria, Comercio y Turismo, a través de resoluciones precisa y determina aspectos relevantes de carácter técnico y sustancial en relación con los derechos de los consumidores. ${ }^{59}$

57 Publicada en el Diario Oficial 44511 del 06 de agosto de 2001. Con la expedición de la circular única se reúnen en un solo cuerpo normativo todas las reglamentaciones e instrucciones generales de la Superintendencia de Industria y Comercio que se encuentran vigentes, con los siguientes propósitos: i) Recopilar, revisar, modificar y actualizar todos los actos administrativos de carácter general expedidos por la Superintendencia de Industria y Comercio. ii) Facilitar a los destinatarios de su misión de protección, vigilancia y control, el cumplimiento, comprensión y consulta de los actos expedidos por esta Superintendencia. iii) Proporcionar a sus funcionarios un instrumento jurídico unificado y coherente que determine con precisión las reglas aplicables a las situaciones concretas que se inscriben dentro de su ámbito de competencia.

58 El título completo se puede consultar en: http://www.sic.gov.co/ documents/10157/53310/Titulo+II+Proteccion-NULIDAD+pvc.pdf/ dfb38a29-18c4-40e2-93db-c2e492706c7c

59 Algunas de las resoluciones son: la Resolución 69916 del 31 de diciembre de 2009, por la cual se determinan las tarifas correspondientes a la contribución por garantías y condicionamientos a que se refiere el artículo 22 de la Ley 1340 de 2009; la Resolución 3530 de 2012, por la cual se establecen las reglas asociadas a la autorización para la venta de equipos terminales móviles en el país, se modifican los artículos 4o, 6o y 14 de la Resolución CRC 3128 de 2011; la Resolución 0957 de 2012, por la cual se expide el reglamento técnico aplicable a talleres, equipos y procesos de conversión a gas natural comprimido
Finalmente, el Gobierno expidió la Ley 1480 de 2011 que introduce el Estatuto del Consumidor, en el cual se "actualizan las normas de protección al consumidor, frente a los cambios de los mercados y los avances de la ciencia jurídica en esta materia". ${ }^{60}$ Este avance legislativo reconoce otras formas de mercadeo y comercialización en donde convergen nuevos productos y tecnologías que, entre otras, generan nuevos riesgos al consumidor.

Uno de los avances que introdujo la Ley 1480 de 2011 fue la figura de la reversión del pago, estipulada en el artículo 51. Durante el trámite legislativo, específicamente en el Informe de ponencia para primer debate ${ }^{61}$ del Proyecto de Ley 252 de 2011 Senado y 089 de 2010 Cámara, se introdujo un capítulo denominado Protección al consumidor de comercio electrónico, con el propósito no solo de regular las operaciones de consumo que se dan en este ámbito, sino de reconocer por primera vez que se trata de un sector en permanente desarrollo que genera constantes modificaciones al mercado y retos a las autoridades responsables de la protección al consumidor. El mismo Informe de Ponencia da cuenta que la redacción del artículo 51 fue propuesta por la Asobancaria, sin mencionar justificación alguna sobre la materia.

para uso vehicular; la Resolución 172 de 2012, por la cual se expide el Reglamento Técnico aplicable a Pilas de Zinc-Carbón y Alcalinas que se importen o fabriquen para su comercialización en Colombia, entre otras.

60 GIRALDO LÓPEZ, Alejandro, CAYCEDO ESPINEL, Carlos Germán y MADRIÑAN RIVERA, Ramón. Comentarios al Nuevo Estatuto del Consumidor. Bogotá D. C.: Legis, 2012, p. 283.

61 Ver Gaceta del Congreso n. ${ }^{\circ} 352$ de 1 de junio de 2011. 
En el Discurso de Instalación del V Congreso de Prevención del Fraude y Seguridad, María Mercedes Cuéllar, presidenta de la Asobancaria, refiriéndose a la innovación de la reversión del pago a través de medios electrónicos en el nuevo estatuto, mencionó que todos los que intervienen en el proceso de pago "deberán definir los procedimientos que permitan hacer procedente la reversión de la transacción financiera. Además, esta disposición legal les impone a los actores que participan en el comercio electrónico, avanzar en el fortalecimiento de las herramientas requeridas para mitigar la posibilidad de efectuar compras fraudulentas o no consentidas por los clientes". 62 Con este pronunciamiento la Asobancaria insta no solo a los intervinientes del pago, tales como bancos e intermediarios, sino también al consumidor como principal agente para evitar el fraude siguiendo recomendaciones de seguridad.

Por lo tanto, la reversión del pago a través de medios electrónicos, si bien se considera una novedad en temas legislativos no lo es en temas prácticos, porque a pesar de que sobre el particular ninguna autoridad se había pronunciado (Congreso, Corte Constitucional, Corte Suprema, Superintendencia de Industria y Comercio) estos se daban dentro de un sistema de mercadeo interno de la empresa o a través de operaciones de reversión en las diferentes entidades financieras, como un mecanismo de protección al consumidor financiero que más adelante se explicará.

62 CUÉLLAR, María Mercedes. Discurso de Instalación V Congreso de Prevención del Fraude y Seguridad. Bogotá, Colombia: Asobancaria, 20 de octubre de 2011 , p. 8.

\section{COMERCIO ELECTRÓNICO EN COLOMBIA}

Debido a que la reversión del pago se desarrolla en el contexto de las relaciones de consumo efectuadas en el comercio electrónico (e-commerce), es importante conceptualizar la incidencia de este nuevo mercado en Colombia, su desarrollo y su regulación aplicable. El comercio electrónico abre el mercado a un contexto sin fronteras y sin barreras claras, al que el consumidor puede acceder desde cualquier lugar del globo y realizar transacciones sobre productos ubicados en otro lugar del planeta.

El comercio electrónico "se refiere a todas las transacciones comerciales realizadas o basadas en sistemas electrónicos de procesamiento y transmisión de información", ${ }^{63}$ incluido el intercambio de información digitalizada entre organizaciones, individuos o ambos para establecer una transacción comercial, ${ }^{64}$ lo que implica el intercambio de dinero y el retorno de un producto o servicio, cuando medie entre estos un pago.

Por otro lado, el comercio electrónico hace referencia a "las transacciones comerciales efectuadas, basadas en el procesamiento y transmisión

63 REMOLINA ANGARITA, Nelson. Desmaterialización, documento electrónico y centrales de riesgo. En: Internet, comercio electrónico \& telecomunicaciones. Bogotá: Legis. Universidad de los Andes, Grupo de Estudios en Internet, Comercio Electrónico, Telecomunicaciones e Informática (GECTI), 2002, p. 4-45.

64 MATUTE, Genaro et al. Del consumidor convencional al consumidor digital: el caso de las tiendas por departamento. Serie Gerencia Global 22. Lima, Perú: Universidad ESAN, 2012, p. 157. 
digitalizada de información, incluyendo textos, sonidos e imágenes visuales realizadas tanto mediante redes abiertas o sistemas cerrados". 65 De esta forma, las nuevas necesidades del mercado y el desarrollo de las nuevas tecnologías de la información han llevado a que los creadores de políticas públicas, los empresarios y en general toda la sociedad, acepten hoy en día que el comercio electrónico es un mecanismo de transformación económica y social.

El artículo 2 literal b) de la Ley 527 de $1999^{66}$ proporciona una definición sobre comercio electrónico en la cual se pueden distinguir tres aspectos. Primero, el campo de aplicación del comercio electrónico se amplía a cualquier relación de índole comercial, incluyendo etapas precontractuales y de ejecución del contrato. Segundo, el medio por el cual se desarrolla este tipo de relaciones es a través de mensajes de datos, lo cual incluye textos, sonidos, imágenes, entre otros. Tercero, enuncia una serie de actividades que pueden ser realizadas a través de este medio, lo cual no restringe que otras más puedan acceder a este mecanismo para la co-

65 HOCSMAN, Heriberto. Negocios en Internet. Buenos Aires, Argentina: Astrea, 2005, p. 134.

66 Establece que el comercio electrónico "Abarca las cuestiones suscitadas por toda relación de índole comercial, sea o no contractual, estructurada a partir de la utilización de uno o más mensajes de datos o de cualquier otro medio similar. Las relaciones de índole comercial comprenden, sin limitarse a ellas, las siguientes operaciones: toda operación comercial de suministro o intercambio de bienes o servicios; todo acuerdo de distribución; toda operación de representación o mandato comercial; todo tipo de operaciones financieras, bursátiles y de seguros; de construcción de obras; de consultoría; de ingeniería; de concesión de licencias; todo acuerdo de concesión o explotación de un servicio público; de empresa conjunta y otras formas de cooperación industrial o comercial; de transporte de mercancías o de pasajeros por vía aérea, marítima y férrea, o por carretera". mercialización de bienes o servicios, por lo tanto la lista es enunciativa y no taxativa. ${ }^{67}$

El artículo 49 de la Ley 1480 de $2011^{68}$ establece que el comercio electrónico se enfocará en la realización de actos, negocios u operaciones entre dos partes, proveedores y consumidores, por medio de mensajes de datos, con el fin de comercializar bienes o servicios. Esta definición se deberá armonizar con la citada por la Ley 527 de 1999 pues no son excluyentes.

En el mismo sentido, el hecho de que el precitado artículo 49 solo estipule como parte al proveedor y no al productor, no implica que los consumidores no puedan ejercer acciones contra el productor que promocione sus bienes o servicios a través del comercio electrónico, pues en primer lugar, tal y como lo señala el artículo 4 de la Ley 1480 de 2011,69 todas las normas sobre consumidor deberán interpretarse a favor del mismo, y este podrá interponer las acciones en contra del productor en los casos señalados en

67 PLATA LÓPEZ, Luis Carlos. La protección a los consumidores en el comercio electrónico. En: Derecho del Consumo: problemáticas actuales. Bogotá, Colombia: Grupo Editorial Ibañez. Universidad Santo Tomás, 2013, p. 780.

68 Artículo 49: Sin perjuicio de lo establecido en el literal b) del artículo 2 de la Ley 527 de 1999, se entenderá por comercio electrónico la realización de actos, negocios $u$ operaciones mercantiles concertados a través del intercambio de mensajes de datos telemáticamente cursados entre proveedores y los consumidores para la comercialización de productos y servicios.

69 Artículo 4: Las disposiciones contenidas en esta ley son de orden público. Cualquier estipulación en contrario se tendrá por no escrita, salvo en los casos específicos a los que se refiere la presente ley. Sin embargo, serán válidos los arreglos sobre derechos patrimoniales, obtenidos a través de cualquier método alternativo de solución de conflictos después de surgida una controversia entre el consumidor y el proveedor y/o productor. Las normas de esta ley deberán interpretarse en la forma más favorable al consumidor. En caso de duda se resolverá en favor del consumidor. 
la ley, sin perjuicio de que la transacción haya sido realizada a través del comercio electrónico.

El procesamiento y transmisión de la información se puede dar a través de EDI (Electronic Data Interchange) e internet. Según el artículo 2 literal e) de la Ley 527 de 2000, ${ }^{70}$ el intercambio de información hace referencia a "[I]a transmisión electrónica de datos de una computadora a otra, que está estructurada bajo normas técnicas convenidas al efecto".

Adicionalmente, la Resolución del 24 de octubre de 1995, de la Federal Networking Council de Ios Estados Unidos, define internet como "un sistema global de información que: 1) está relacionado lógicamente por un único espacio global de direcciones basado en el protocolo IP o en sus extensiones; 2) Es capaz de soportar comunicaciones usando el conjunto de protocolos TCP/IP; 3) Proporciona, usa, o hace accesible, de manera pública o privada, servicios de alto nivel en capas de comunicaciones (...)" ${ }^{71}$ Con ello se define el marco de aplicación para las transacciones hechas por cualquier consumidor en Colombia a través del comercio electrónico como medio para acceder al mercado, mercado que resulta ser infinito y amplio por eliminar las barreras fronterizas.

70 "Por medio de la cual se define y reglamenta el acceso y uso de los mensajes de datos, del comercio electrónico y de las firmas digitales, y se establecen las entidades de certificación y se dictan otras disposiciones." Diario Oficial n. ${ }^{\circ} 43.673$, de 21 de agosto de 1999 :

71 Consultar el texto completo de la Resolución en: http://www.nitrd.gov/ archive/fnc-material.aspx Adicionalmente, sobre la historia de la Internet: http://www.internetsociety.org/es/breve-historia-de-internet. Sobre aspectos técnicos y jurídicos que estableció la UIT sobre Internet y servicios conexos: http://www.itu.int/ITU-T/special-projects/ip-policy/ final//PPolicyHandbook-S.pdf
Según el más reciente estudio ${ }^{72}$ sobre penetración de las nuevas tecnologías de la información en la sociedad global, entre el año 2005 y el 2013 hubo un alza tanto en la demanda como en la oferta de los servicios de telecomunicaciones, y para el año 2013 se espera que 2,7 billones de personas se encuentren en línea (online) diariamente, es decir, casi el $40 \%$ de la población mundial. Finalmente, el estudio señala que para el año 2013, aproximadamente 750 millones de hogares tendrían acceso a internet.

Por otro lado, Technology Tracker realizó una encuesta a 1.005 personas en Colombia ${ }^{73}$ con el fin de determinar el uso de internet en el país. Dicho estudio arrojó los siguientes datos: el $79,8 \%$ de la población asegura usar internet, de este porcentaje, la población entre los 15 y los 17 años tienen un 100\% de acceso, mientras que del grupo entre los 45 y los 55 años apenas el 55,9\% dice usarlo, convirtiéndose en el rango de edad con menor acceso. El 54\% de los usuarios de internet asegura utilizarlo todos los días de la semana, y solo el $12 \%$ indica que accede una o dos veces por semana. Entre el $20,2 \%$ de colombianos encuestados que no utilizan internet, la mayor causa es el no saber usarlo e incluso no saber usar un computador (58\%). Este resultado es un indicador relevante

72 International Telecommunication Union (ITU). The World in 2013: ICT Facts and Figures. Estados Unidos. 2013. Disponible en: http://www. itu.int/en/ITU-D/Statistics/Documents/facts/ICTFactsFigures2013.pdf. Consultado el 23 de abril de 2013

73 CORPORACIÓN COLOMBIA DIGITAL (CCD). Estadísticas de uso de Internet en Colombia. 2012. Disponible en: http://www.colombiadigital.net/entorno-tic/noticias/tic-en-colombia/item/4087estad\%C3\%ADsticas-de-uso-de-internet-en-colombia.html. Consultado el 25 de abril de 2013. 
para determinar que la penetración de internet en Colombia todavía no es completa, y para que la mayoría de la población pueda acceder a este servicio es necesario crear programas de información y educación sobre su acceso y manejo.

Sin embargo, llama la atención que un estudio realizado por Visa en América Latina ${ }^{74}$ sobre ecommerce, estableció que las ventas en el comercio electrónico en esta parte del globo se duplicaron en dos años llegando a registrar ventas de alrededor de los US\$ 43 millones durante el 2011. Este desarrollo se refleja en una nueva forma de vida a la que la sociedad debe irse adaptando, así como a los constantes cambios que genera el e-commerce, estableciendo no solo una nueva plataforma de negocios sino también un manejo que permita cerrar las brechas entre el consumidor y el proveedor o productor.

Veamos qué pasa con las relaciones. De acuerdo con la naturaleza de negocios que se manejan en el contexto del comercio electrónico se pueden dar diferentes relaciones: i) (B2B) $\mathrm{Ne}$ gocio a negocio; ii) (B2C) Negocio a consumidor; iii) (G2B) Gobierno a negocio; iv) (G2C) Gobierno a consumidor; v) (C2C) Consumidor a consumidor; vi) (P2P) Entre pares. ${ }^{75}$ Teniendo en cuenta que nuestro objeto de estudio se centra en la relación de asimetría entre el consumidor y el proveedor o productor, nos centraremos en la relación (B2C) o negocio a consumidor.

74 CONTRERAS S., Jaime. Estudio de comercio electrónico en América Latina. Elías Selman Carranza, 2012, p. 8.

75 MATUTE, G. Óp. cit.
El modelo de negocios (B2C) se puede definir simplemente como la venta de bienes y servicios a los consumidores a través de internet. Este tipo de negocios se incrementa en la medida en que más usuarios tengan acceso a la Web. Se establecen como portales que ofrecen productos, servicios o contenido por medio de estrategias de desarrollo para llegar directamente al consumidor final. Actualmente, las ventas realizadas a través de internet representan una proporción considerable de las ventas comerciales totales. Se estima que en el año 1999 tenían acceso a internet 300 millones de usuarios, de los cuales una cuarta parte realizaron compras en línea en sitios de comercio electrónico, por un valor aproximado de 110.000 millones de dólares EE. UU. ${ }^{76}$ Una aproximación estima que para el presente año (2013) las ventas de comercio electrónico de empresa a consumidor superarán los 1,25 billones de dólares EE. UU. ${ }^{77}$

Este tipo de modelo de negocio se basa en que las empresas ofrecen y venden sus productos al público en general, habitualmente mediante catálogos en los que se utilizan programas informáticos de carro de compras. ${ }^{78} \mathrm{~A}$ pesar del escaso valor de las transacciones de comercio electrónico B2C, ese tipo de comercio es el que

76 ORGANISATION FOR ECONOMIC CO-OPERATION AND DEVELOPMENT (oecd). E-commerce: impacts and policy challenges. EE. UU. 2000. Disponible en: http://www.oecd.org/eco/economicoutlo okanalysisandforecasts/2087433.pdf. Consultado el 27 de abril de 2013.

77 MONTAQIM, Abdul. Global e-commerce sales sales will top $\$ 1,25$ trillon by 2013. En: Technology. EE. UU.: Internet Retailer, 2012, p. 3.

CHAVES ALVARADO, Daniel Augusto. Perfil del internauta colombiano y metodología para e-business B2C en Colombia. Bogotá, Colombia: Universidad de los Andes. Facultad de Administración de Empresas, 2006, p. 302. 
ha recibido más atención, en parte porque los responsables de la adopción de políticas se han interesado profundamente por cuestiones como la confianza de los consumidores y la protección de los datos. ${ }^{79}$ Además, porque "[l]a adopción de tecnologías de Comercio Electrónico permite que las compañías respondan con rapidez a las presiones competitivas, ya que mejoran las operaciones internas y facilitan las transacciones de negocios". 80

El Estado colombiano no desconoce que la tecnología y la sociedad de la información avanzan constantemente. Prueba de ello es que en el Estatuto del Consumidor, el artículo 51 establece que la figura de la reversión aplica para la compra/venta de bienes que se realicen mediante "mecanismos de comercio electrónico" tales como, "Internet, PSE y/o call center y/o cualquier otro mecanismo de televenta o tienda virtual", reconociendo así que existe un mercado en línea que tiene prerrogativas y circunstancias especiales a diferencia del mercado habitual.

\section{A. Medios electrónicos de pago}

El proceso de pago ha venido evolucionando y lo seguirá haciendo debido al aumento y desarrollo de las nuevas tecnologías. Sin embargo, resulta de gran importancia identificar la diferencia entre medios de pago y sistemas de pago en línea y su incidencia en el ámbito nacional.

79 UNCTAD, IER 2004.

80 ROB, P. y CORONEL, C. Sistemas de bases de datos: diseño, implementación y administración. $3^{a}$ ed. México D. F.: Cengage Learning, 2003, p. 78.
El pago se ha catalogado como una forma de extinguir las obligaciones. Consiste en la satisfacción, ejecución o cumplimiento de la presentación debida por el deudor que puede ser de dar, hacer o no hacer. ${ }^{81}$ Sin el ánimo de realizar un análisis histórico sobre el pago, es necesario hacer algunas acotaciones sobre los medios de pago.

El primer medio de pago que existió en la sociedad fue el trueque o intercambio de bienes $y$ servicios, dependiendo de las necesidades del entorno. A medida que las distancias se ampliaron y las fronteras crecieron, se inició el trato, figura en que la palabra era el elemento de mayor credibilidad. La moneda es el tercer medio de pago; fue acuñada en Roma y sigue siendo el respaldo sobre ese valor que hay depositado en algún sitio el que genera la facilidad de mover el dinero. ${ }^{82}$ Con el desarrollo de la tecnología, la moneda se ha logrado materializar en diferentes formas, tales como las tarjetas de crédito y débito, los cheques, entre otros. Esta evolución de los medios de pago ha generado su inclusión en el comercio electrónico, ampliando significativamente el concepto y el campo de aplicación.

Debido a que cada vez es más frecuente la venta de bienes y servicios a través de redes telemáticas, todo el proceso desde la oferta hasta la confirmación se materializa a través de medios

81 Ver Art. 1626 del Código Civil.

82

LAGUADO GIRALDO, Roberto. Estudios jurídicos sobre comercio electrónico. Bogotá, Colombia: Cámara de Comercio de Bogotá y Pontificia Universidad Javeriana, 2006, p. 266. 
digitales. Dentro de este proceso, el comerciante emite una oferta que es recibida por usuarios indeterminados en la red, algunos de los cuales manifiestan su aceptación y proceden a realizar el pago utilizando medios electrónicos.

Es importante señalar las categorías en que se dividen los distintos instrumentos de pago electrónico que operan en Colombia. En primer lugar está la tarjeta bancaria, sin duda la más popular de las formas de pago empleadas en el comercio electrónico, posiblemente por contar con medidas de seguridad y por la fiabilidad para su uso. Estas han abarcado tres modalidades en la contratación electrónica, en donde se emiten órdenes de pago tales como: I) Emisión y posterior comunicación de los datos de la tarjeta, vía telefónica o fax; este uso ha ido desapareciendo por su falta de agilidad en la contratación, teniendo en cuenta que muchas veces las transacciones se realizan entre países o continentes distintos. II) Emisión a través de un formulario Web con conexión protegida mediante un canal seguro. Este uso introdujo

83 Estatuto Orgánico del Sistema Financiero. Artículo 325 numeral $2^{\circ}$, 326. Ley 964 de 2005, artículo 75 numeral primero del párrafo tercero.

84 Sus adquirentes pagan por un bien o servicio en forma previa a la utilización de este.

85 SUPERINTENDENCIA FINANCIERA DE COLOMBIA. Concepto 2012021788-002 del 27 de marzo de 2012.

86 SUPERINTENDENCIA FINANCIERA DE COLOMBIA. Concepto 2008081133 del 9 de febrero del 2009.

87 El Decreto 1981 de 1988 establece que una persona capta dineros del público de forma masiva y habitual cuando ha realizado operaciones en las que no se prevé contraprestación alguna; estas conforman más de 50 obligaciones o se realizan con más de veinte (20) personas; la sumatoria de estas supera el $50 \%$ del patrimonio líquido del receptor del dinero; o hayan sido el resultado de haber realizado ofertas públicas o privadas a personas innominadas. que los datos de las tarjetas viajaran por la red protegidos por una conexión que, en principio, impedía el acceso a los datos a otros usuarios. Sin embargo, en un campo donde el desarrollo tecnológico avanza rápidamente, resulta costoso y arduo mantener un nivel de seguridad razonable, basándose únicamente en los canales de transmisión. III) Emisión en un formulario Web con conexión segura y datos cifrados. Este nuevo uso plantea soluciones tecnológicas que, además de una comunicación por un canal seguro, añade sistemas de codificación de los datos objeto de envío. Dentro de este medio de pago existen diferentes modalidades, que se describen en el cuadro 2. 


\section{Cuadro 2. Modalidades de tarjetas bancarias}

\begin{tabular}{|c|c|}
\hline Modalidad & Concepto y definición \\
\hline $\begin{array}{c}\text { Tarjetas de } \\
\text { crédito }\end{array}$ & $\begin{array}{l}\text { Dispositivo plástico que cuenta con una banda magnética en la que se almacena información con la } \\
\text { identificación de su dueño y otros datos relacionados, que le permiten a su titular o usuario, dispo- } \\
\text { niendo de un crédito de la entidad que la emite (emisor), adquirir bienes o servicios en establecimien- } \\
\text { tos afiliados al correspondiente sistema. El emisor de las tarjetas de crédito es vigilado por la Superin- } \\
\text { tendencia Financiera, por tratarse de captación de recursos del público y ser un servicio prestado por } \\
\text { una entidad vigilada, en este caso el establecimiento de crédito. }{ }^{83}\end{array}$ \\
\hline $\begin{array}{c}\text { Tarjetas } \\
\text { débito }\end{array}$ & Dispositivo plástico que permite hacer pagos a partir del dinero que una persona tenga en una cuenta. \\
\hline $\begin{array}{c}\text { Tarjeta } \\
\text { monedero/ } \\
\text { prepago }^{84}\end{array}$ & $\begin{array}{l}\text { - En Colombia no existe reglamentación al respecto ni prohibición para su emisión. } \\
\text { - La emisión y recaudo de dinero no están vigilados por la Superintendencia Financiera, por no con- } \\
\text { siderarse dentro de los supuestos de captación masiva. }{ }^{85} \\
\text { - Pueden ser emitidas con la finalidad de adquirir o comprar bienes o servicios, único propósito con } \\
\text { que cuentan. } \\
\text { - El recaudo de los recursos debe corresponder a la persona natural o jurídica que comercializa los } \\
\text { distintos bienes o servicios y no por un tercero. }{ }^{86} \\
\text { - Su emisión sin el cumplimiento de las anteriores condiciones podría conllevar la captación no au- } \\
\text { torizada de dineros en forma masiva. }{ }^{87}\end{array}$ \\
\hline
\end{tabular}

Fuente: elaboración propia.

En segundo lugar encontramos el dinero electrónico (e-money), ${ }^{88}$ esto es, la representación de un valor abstracto, admitido para la realización de intercambios y respaldado por una autoridad. Esta modalidad, en lugar de papel opera con bits, concretamente con cupones criptográficos y tiene las siguientes características: i) Goza de aceptación universal como medio de pago; ii) El pago no depende de la existencia de fondos en una cuenta ni de la concesión de crédito por parte de un tercero; iii) Prevalece el anonimato, a diferencia de las tarjetas bancarias que dejan un rastro fácil de seguir y permiten construir un perfil del titular. ${ }^{89}$

88 Sobre el particular puede consultarse adicionalmente: RICO CARRILLO, Marililiana. Nuevas alternativas de pago en internet: el dinero electrónico y los sistemas de micropagos. En: Revista de Derecho Privado. Dic. 2002, vol. 16, n. ${ }^{\circ} 29$, p. 139-152.

ARBELÁEZ, María Angélica y ZULUAGA, Sandra. Medios de pago
Su funcionamiento se encuentra asociado a dos fases: en la primera, denominada creación del dinero electrónico, el usuario una vez convertido en titular de una cuenta corriente en una entidad bancaria que emite moneda electrónica, previa petición al banco, mediante un software suministrado por la entidad puede crear y gestionar una cuenta de dinero electrónico en la que tendrá la facultad tanto de crear e-money como de manejar dinero que tenga en su cuenta real. Al disponer de dinero electrónico el software gestor de la cuenta le atribuye a cada "cybermoneda" 90 un número de serie aleatorio que es firmado digitalmente por el usuario y en-

electrónicos en Colombia: evolución y perspectivas. Bogotá, Colombia: Fedesarrollo, 2006, p. 136.

90 Término adoptado en RICO CARRILLO, Marililiana. Óp. cit, p. 139152. También su obra: El pago electrónico en internet: estructura operativa y régimen jurídico. España: Thomson Reuters Aranzadi, 2012. 
viado al banco para que este le atribuya un valor económico determinado. Recibido por el banco, este procede a verificar la firma digital y a comprobar la identidad del cliente y la integridad del mensaje. Confirmados los datos, el banco firma digitalmente la "cybermoneda" y simultáneamente el valor determinado es descontado de la cuenta tradicional del titular. Finalmente, el titular recibe la cibermoneda firmada por el banco con un valor determinado, y puede usarla como medio de pago en el comercio electrónico. ${ }^{91}$

\section{Cuadro 3. Diagrama del proceso de creación del dinero electrónico}

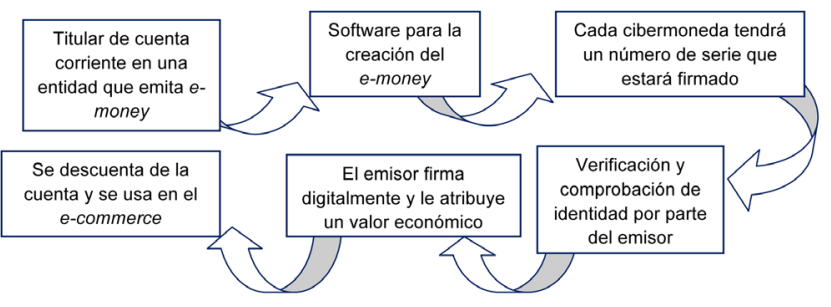

Fuente: elaboración propia.

La segunda fase corresponde al pago mediante dinero electrónico. Llegado el momento del pago, el titular, mediante el software de gestión, transfiere al comerciante "cybermonedas" por el importe de la deuda. Recibidas por el comerciante, este se conecta con el banco y verifica la autenticidad de las cybermonedas", comprobación que realiza la entidad bancaria constatando tanto su firma electrónica en las "cybermonedas" remitidas por el comerciante como el hecho de que las "cybermonedas" no han sido usadas. Realizadas estas comprobaciones, la

91 ARBELÁEZ, María Angélica y ZULUAGA, Sandra. Óp. cit., p. 140. entidad bancaria ingresa en la cuenta del comerciante la cantidad económica equivalente al valor de las monedas.

El tercer medio de pago electrónico son las órdenes de pago y los cheques electrónicos. Esta modalidad le permite al cliente pagar directamente desde su cuenta corriente o de ahorros personal, y se procesa a través del sistema que utilizan los bancos para los depósitos y pagos electrónicos. A partir de los números impresos en la parte inferior del cheque de papel, el sistema transforma la información de la cuenta en un elemento de transferencia de fondos electrónica estándar que luego procesa a través de la red de la Cámara de Compensación Automatizada (Automated Clearing House - $\mathrm{ACH}$,). Este es el mismo sistema que se utiliza para las transacciones de cajeros automáticos y depósito directo de cheques de planilla. ${ }^{92}$

Cabe aclarar que la oferta de bienes y servicios por medio del comercio electrónico permite también que el pago de la operación se realice a través de medios tradicionales, con lo cual el consumidor, en algunos casos, tendrá la posibilidad de imprimir el recibo, la orden o el código de pago y cancelarlo posteriormente a través de medios que podríamos denominar off line, como i) el establecimiento bancario, ii) entidades de recaudo internacional que tienen sedes locales, como por ejemplo Efecty; iii) entidades de recaudo nacional que actúan como intermediarios del pago, como por ejemplo Baloto; o iv)

92 Ibíd., p. 145. 
corresponsales no bancarios como por ejemplo Movilred.

Recordemos que la Ley 1480 en su artículo 51 establece que la reversión del pago aplicará para operaciones en las cuales se haya "utilizado para realizar el pago una tarjeta de crédito, débito o cualquier otro instrumento de pago electrónico". La Recomendación 97/489/CE, del 30 de julio de 1997, ${ }^{93}$ establece que dentro de este instrumento hay que aclarar dos modalidades: el instrumento de pago de acceso a distancia y el dinero electrónico.

El instrumento de pago de acceso a distancia lo define como aquel que le permite a su titular acceder a los fondos de su cuenta en una entidad y autorizar el pago a un beneficiario, precedido de determinados códigos de identificación personal o prueba similar de identidad. $Y$ el instrumento de dinero electrónico, lo define como aquel que consiste en recargar una tarjeta en la que se almacenan electrónicamente los importes correspondientes. Estos dos medios de pago permiten a su titular efectuar diferentes transacciones con otros actores.

Teniendo en cuenta que Colombia no tiene una definición sobre instrumentos de pago electrónico, si acogemos la definición de la Directiva antes mencionada y realizamos el análisis del artículo sobre la reversión, estaríamos ante un escenario en el cual la reversión del pago solo aplicaría a los consumidores que paguen sus

93 Relativa a las transacciones efectuadas mediante instrumentos electrónicos de pago, en particular, las relaciones entre emisores y titulares de tales instrumentos. transacciones por medio de tarjetas crédito, débito, recargables, e-money o cheques electrónicos, con lo cual se dejaría por fuera las órdenes de pago que se cancelen con medios off line. Es decir, si un usuario solicita determinado producto a través de internet y prefiere descargar el recibo, hacer el pago en un punto bancario y luego enviar la confirmación del pago a través de internet, esta venta no aplica para la reversión, situación que resultaría incoherente con el objetivo y finalidad de la reversión, que es la devolución del dinero cuando las ventas se realicen en el contexto del comercio electrónico y el consumidor haya sido objeto de determinadas situaciones, que más adelante se decantarán.

\section{REVERSIÓN DEL PAGO}

Sabiendo entonces, i) que el desarrollo de la tecnología se da constantemente y que esto conlleva nuevas prácticas comerciales y riesgos; ii) que el derecho del consumo se basa en la relación que existe entre los consumidores y los proveedores o distribuidores; iii) que los avances legislativos son respuesta a las necesidades de la sociedad; iv) que la aplicación de la figura de la reversión se estableció en el comercio electrónico como uno de los campos del derecho del consumo; y v) que la reversión se ejerce cuando el pago de una transacción se haya efectuado por medio de mecanismos de comercio electrónico, se procede a señalar en qué consiste la reversión, las situaciones en las cuales es aplicable y el procedimiento establecido.

El artículo 51 del Estatuto del Consumidor, (Ley 1480 de 2011), tiene como objetivo principal 
la devolución del dinero en determinadas circunstancias, obligación que recae en todos los participantes del proceso de pago, cuando el consumidor lo solicite. Según la mencionada Ley, existen situaciones generales en las cuales el consumidor podrá reversar la operación: 1) Cuando el consumidor haya sido objeto de fraude; 2) Cuando corresponda a una operación no solicitada; 3) Cuando el producto adquirido no sea recibido; 4) Cuando el producto entregado no corresponda a lo solicitado; 5) Cuando el producto sea defectuoso; y 6) cuando el pago corresponda a cualquier servicio u obligación de cumplimiento periódico, por cualquier motivo, con algunas restricciones que se analizarán más adelante.

Las anteriores situaciones se pueden clasificar en tres grupos identificables por características comunes en cada uno. El primero de ellos hace referencia a las situaciones en las cuales el consumidor es sujeto de fraude o se trata de una operación no solicitada y, por tanto, el consumidor no ha dado su consentimiento para efectuar la operación. Por ejemplo, cuando un tercero, abusando de medios tecnológicos toma los datos financieros de un consumidor para cargar en la cuenta de este operaciones sin su consentimiento, o cuando a pesar de mediar consentimiento para un producto se cargan a la cuenta del consumidor otros productos o el mismo en varias unidades. Sobre estas situaciones es pertinente mencionar que, si bien los medios virtuales y digitales constituyen una nueva herramienta de comunicación con el mundo, poseen ventajas y desventajas, una de estas es que existen personas inescrupulosas que valiéndose de conocimientos tecnológicos o de sistemas vulneran contraseñas, usuarios, cuentas y demás para cometer delitos informáticos.

Dentro de estas prácticas fraudulentas ${ }^{94}$ asociadas al derecho del consumo, podemos encontrar las siguientes: I) Claves programáticas espías o software espía, utilizados para sustraer información en forma remota y física, preferiblemente aquella que le permita al ciberdelincuente validarse en el sistema bancario, suplantando a la víctima. II) Estafas a través de subastas en línea. En este caso, los ciberdelincuentes ofertan sus servicios o productos a través de software de aplicaciones ilegales que, además, pueden ser una vía para la estafa ya que suelen incumplir reglas de envío y de calidad de los productos solicitados. ${ }^{95} \mathrm{III}$ ) Phishing. Esta modalidad se inicia con un mensaje de datos enviado al usuario en nombre de su entidad financiera, invitándolo a dar click en algún enlace que en realidad corresponde a una página que podríamos denominar fantasma, pues no pertenece a la entidad bancaria pero se usa para recolectar la información del cliente. IV) Vishing. Es una práctica que consiste en utilizar medios exter-

94 La Federal Commision Trade (FTC) de Estados Unidos, organismo que supervisa la competencia y se encarga de la protección de los consumidores, publicó una lista con los 10 fraudes más comunes que se pueden realizar a través de Internet. Este decálogo de prácticas se puede consultar en: http://www.delitosinformaticos.com/estafas/10estafas. shtml

95 En Colombia, la Policía Nacional a través de la Unidad Policial para delitos informáticos se encarga de la investigación relacionada con estos temas. Para una mayor información consultar: http://www.policia. gov.co/portal/page/portal/UNIDADES_POLICIALES/Direcciones_tipo_ Operativas/Direccion_Seguridad_Ciudadana/Planes_de_Seguridad/ Recomendaciones_de_seguridad/delitos_informaticos. Consultado el 14 de mayo de 2013. 
nos a la entidad bancaria, como llamadas, para solicitar al cliente incauto que se comunique a un número determinado y así poder recolectar sus datos bancarios para realizar el fraude. V) Smishing. Consiste en el uso de mensajes de texto a celulares aleatorios para engañar a los usuarios y obtener información personal y bancaria. Esta práctica puede ir combinada con el phising. ${ }^{96}$

Sobre el particular cabe señalar que según un informe de la Asobancaria, las quejas por fraudes electrónicos en el 2005 fueron 277, cifra que correspondió a un $2 \%$ del total de las quejas; en el 2006 este porcentaje aumentó a un 14\%.97 De igual forma, en el informe estadístico de quejas de establecimientos bancarios recibidas en el 2012 por la Superintendencia Financiera, los motivos de las reclamaciones fueron en su orden: revisión y/o liquidación (24\%), cobro servicios y/o comisiones (21\%), fallas en cajero automático (17\%), descuentos injustificados (16\%), no remisión de información al cliente (12\%), entre otros. ${ }^{98} \mathrm{~A}$ pesar de que la Superfinanciera no clasifica las reclamaciones por delitos informáticos, estos pueden estar asociados a cobros o comisiones injustificadas, pues el uso de datos bancarios por parte de los ciberdelincuentes lleva a que se carguen a la cuenta del titular

96 La Asobancaria ha gestionado campañas en contra de estas prácticas y ha emitido canales para conocer las recomendaciones de seguridad que deben tener los usuarios en internet. Mayor información en: http:// www.asobancaria.com/portal/page/portal/Asobancaria/seguridad/

CÁRDENAS SANTAMARÍA, Patricia. Quejas: indicador de calidad del servicio bancario. En: La Semana Económica, 2006, vol. 562, p. 6.

98

Informe Estadístico que puede ser consultado en: http://www.superfinanciera.gov.co/ConsumidorFinanciero/analisisquejas.html cobros sobre transacciones que nunca realizó ni autorizó. Según el reporte Symantec Internet Secuirty Thretat, de abril de 2011, en el 2010 se encontraron 4.989 nuevas vulnerabilidades en elementos tecnológicos, aproximadamente 95 por semana; existen más de 403 millones de variantes de malware (software malicioso o mal intencionado); y los ataques se siguen moviendo hacia los dispositivos móviles, los cuales con respecto al 2010 tuvieron más del 93\% en vulnerabilidades y más del $1.116 \%$ de malware. ${ }^{99}$

En el proceso de reversión del pago interactúan el proveedor o productor, el emisor del instrumento de pago y el consumidor. De ello se desprende que el emisor del instrumento de pago se encuentra vigilado por la Superintendencia Financiera de Colombia, y que esta entidad será también competente para tramitar lo relacionado con la protección al consumidor financiero. Debido a esta competencia, dicha entidad dispone que los establecimientos de crédito tienen la obligación de brindar "productos y servicios con estándares de seguridad y calidad de acuerdo con las condiciones ofrecidas y las obligaciones asumidas por las entidades vigiladas". 100 Por ello, en la Circular Externa 022 de $2010^{101}$ determinó los requerimientos mínimos de seguridad y calidad para realizar operaciones a través

99 SYMANTEC. Symantec Internet Secuirty Thretat. EE. UU. 2012. Disponible en: http://www.symantec.com/security_response/publications/ threatreport.jsp. Consultado el 20 de mayo de 2013.

100 Literal a) del artículo $5^{\circ}$ de la Ley 1328 de 2009

101

El documento completo de la Circular Externa 002 de 2010 se puede consultar en: http://www.superfinanciera.gov.co/ siguiendo el enlace Normas/Normativa/Circulares externas/ 022/anexos. Consultada el 3 de mayo de 2013 
de internet, y estableció una serie de medidas encaminadas a fortalecer la seguridad y la calidad en el manejo de la información de los clientes y usuarios de las entidades vigiladas, bien sea que acudan a cualquiera de los instrumentos para la realización de operaciones (tarjetas débito, crédito, dispositivos móviles y órdenes electrónicas para la transferencia de fondos) o a los canales de distribución de servicios financieros (oficinas, cajeros automáticos, receptores de cheques, receptores de dinero en efectivo, POS, sistemas de audio respuesta -IVR-, centros de atención telefónica -Call Center, Contac Center- sistemas de acceso remoto para clientes RAs, internet y dispositivos móviles), a través de los cuales estas prestan sus servicios.

En relación con las operaciones realizadas a través de internet, ${ }^{102}$ el numeral 4.9 del instructivo en comento indica que las entidades deben cumplir, como mínimo, con los siguientes requerimientos: I) Implementar los algoritmos y protocolos necesarios para brindar una comunicación segura. II) Realizar como mínimo dos veces al año una prueba de vulnerabilidad y penetración a los equipos, dispositivos y medios de comunicación usados en la realización de operaciones monetarias por este canal. Sin embargo, cuando se realicen cambios en la plataforma que afecten la seguridad del canal, deberá realizarse una prueba adicional. III) Promover y poner a disposición de sus clientes mecanismos que

102 Al respecto cabe resaltar algunos fallos que ha emitido la Superintendencia Financiera de Colombia en relación con transacciones no reconocidas por los consumidores, por transacciones sin su consentimiento a través de internet, tales como: Fallos de la Delegatura para Funciones Jurisdiccionales. Expediente: 2012-0020, Radicado interno: 201250156; Expediente: 2012-0051. Radicado interno: 2012070946; Expediente: 2012-0061, Radicado interno: 2012073104. reduzcan la posibilidad de que la información de sus operaciones monetarias pueda ser capturada por terceros no autorizados durante cada sesión. IV) Establecer el tiempo máximo de inactividad, después del cual se deberá dar por cancelada la sesión, exigiendo un nuevo proceso de autenticación para realizar otras operaciones. V) Informar al cliente, al inicio de cada sesión, la fecha y hora del último ingreso a este canal. VI) Implementar mecanismos que permitan a la entidad financiera verificar constantemente que no sean modificados los enlaces (links) de su sitio Web, ni suplantados sus certificados digitales, ni modificada indebidamente la resolución de sus Domain Name System (DNS). ${ }^{103}$ Lo anterior evidencia que los ataques en el comercio electrónico, por personas malintencionadas, no son ajenos a la realidad, y que el Estatuto del Consumidor tuvo esto presente al establecer una alternativa para cuando el ciberconsumidor sea víctima de ellos, sin perjuicio de las investigaciones de otro tipo a las que haya lugar.

El segundo grupo de situaciones en las que el consumidor podrá reversar la operación hace alusión a las calidades del producto, es decir, cuando el producto que solicitó le llega con algún defecto, no recibe lo solicitado o simplemente no lo recibe. Estas situaciones enmarcan los riesgos que corre el consumidor cuando hace uso del comercio electrónico, pues en la mayoría de casos no puede percibir materialmente el producto, lo que de una u otra forma afecta su capacidad de decisión.

103 SUPERINTENDENCIA FINANCIERA. Concepto n. ${ }^{\circ}$ 2011062919-001 del 6 de septiembre de 2011. 
Ya que la reversión del pago es un derecho en cabeza del consumidor y una obligación en cabeza de los participantes del pago, será decisión del consumidor ejercerlo o no. Por ejemplo, en el caso de que el producto sea defectuoso podrá optar por iniciar un proceso de responsabilidad por daños por producto defectuoso ${ }^{104} \mathrm{o}$ acogerse al régimen de garantías ${ }^{105}$ que establece el mismo Estatuto.

En el tercer grupo se puede ubicar una situación en la que no necesita mediar justificación alguna respecto de algún vicio en el consentimiento o en las calidades del producto; al contrario, opera por el 'capricho' o decisión del consumidor, ${ }^{106}$ siempre y cuando la reversión se dé bajo ciertas circunstancias, tales como: i) Debe tratarse de pagos correspondientes a cualquier servicio $u$ obligación de cumplimiento periódico. ii) El pago debe haberse realizado a través de una operación de débito automático. Sobre el particular, la Superintendencia Financiera ha establecido que “[e]n el débito automático los consumidores financieros autorizan pagos a los bancos para que con cargo a los depósitos de su cuenta bancaria (ahorros o corriente) se debiten dineros para el pago de determinados productos". ${ }^{107}$ iii) Debe existir autorización previa del consumidor. Es el caso de un consumidor que decide

104 Artículo 19 al 22 de la Ley 1480 de 2011.

105 Artículo 7 al 18 de la Ley 1480 de 2011. Decreto reglamentario 735 del 17 de abril de 2013, por medio del cual se reglamenta la efectividad de la garantía prevista en los artículos 7 y siguientes de la Ley 1480 de 2011.

106 Parágrafo $2^{\circ}$ artículo 51 de la Ley 1480 de 2011

107 SUPERINTENDENCIA FINANCIERA. Concepto n. ${ }^{\circ}$ 2011054054-002 del 6 de septiembre de 2011 . libremente autorizar el pago de la suscripción a una revista, el servicio de telefonía móvil o de internet, entre otros, a través de un débito automático de su cuenta a la cuenta del proveedor o productor, y cualquier día decide que prefiere reversar el pago y optar por otros mecanismos de pago. Esta opción que tiene el consumidor puede ser interpretada en contra del empresario, pues al reversar el pago de una obligación o servicio es probable que este se esté ejecutando o ya se haya ejecutado, lo cual en principio no cumpliría con las cargas de cada una de las partes en cuanto a pagar por un bien o servicio recibido, y a entregar en debida forma ese producto. Sin embargo, cabe aclarar que la reversión se efectúa sobre el pago de la obligación, no sobre el contrato mismo, es decir, sobre la relación de consumo. Así, en el ejemplo de reversión del pago de la suscripción a una revista, este se efectúa sobre el valor de ese período y no sobre la relación de consumo. Por consiguiente, el empresario tiene derecho a cobrar el valor sobre el bien o servicio ejecutado o en ejecución por otros medios. Esta situación solo cambia entonces el mecanismo de pago de la obligación y no la obligación misma.

\section{A. Aplicación en bienes y servicios}

Dado que la reversión, como mecanismo para la devolución del dinero bajo determinados presupuestos, se traduce en un derecho a favor del consumidor, resulta importante señalar si este derecho aplica tanto para bienes como para servicios. El artículo 51 de la citada Ley no hace mención explícita sobre si la reversión aplica a servicios, salvo en el parágrafo segun- 
do en donde estatuye que, cumpliendo algunos requisitos, se podrá efectuar la reversión sobre obligaciones o servicios de carácter periódico. Sin embargo, en varios acápites del mismo artículo se hace referencia al producto ${ }^{108}$ como el elemento al cual se le aplica la reversión del pago. Remitiéndonos al artículo $5^{\circ}$ de la Ley, encontramos que producto se entiende "Todo bien o servicio", lo cual se traduciría en que la reversión en sus 5 modalidades iniciales aplica para cualquier bien o servicio y la $6^{\text {a }}$ a los servicios de cumplimiento periódico.

A pesar de ello, en una respuesta de la Superintendencia de Industria y Comercio ${ }^{109}$ acerca del tema, aparece que los incisos $1^{\circ}$ al $4^{\circ}$ del artículo 51 solo aplican sobre bienes y no sobre servicios, aduciendo para ello que el parágrafo $2^{\circ}$ del mismo artículo señala los casos en los que procede la reversión para determinados servicios. Realizar esta conclusión, sin observar que el artículo hace referencia a productos y no a bienes resulta desacertada, y de interpretarse de esa forma se dejarían por fuera del campo de aplicación servicios que, a pesar de no ser periódicos, pueden ser defectuosos, no solicitados o no recibidos.

\section{B. Finalidad}

El objetivo principal de la reversión es la devolución del dinero o su abono en la cuenta del consumidor. De esta finalidad se desprenden varias

108 Artículo 51 de la Ley 1480 de 2011: "el producto adquirido, no sea recibido, (...) el producto entregado no corresponda, (...) deberá devolver el producto".

109

SUPERINTENDENCIA DE INDUSTRIA Y COMERCIO. Consulta. Radicado 12-70858-3-0 del 25 de junio de 2012. características importantes para la adecuada aplicación de la figura. La devolución del dinero se expresa como una obligación en cabeza del proveedor, productor e intervinientes en el proceso de pago, según corresponda.

Realizando una analogía con la devolución de dinero de que trata la garantía y el derecho de retracto, ${ }^{110}$ se puede establecer que la Superintendencia de Industria y Comercio ha entendido que la devolución del dinero tiene determinadas prerrogativas. (I) Debe ser íntegra, es decir, debe corresponder al precio de venta del bien y debe ser libre de gravámenes, ${ }^{111}$ de modo que el proveedor o el productor no podrán a su arbitrio descontar costos operativos u otros aduciendo el ejercicio del derecho. (II) Debe ser independiente de los costos o gastos conexos. Sobre este punto el derecho de retracto establece que, cuando el consumidor decida hacer uso de este mecanismo para resolver el contrato y reintegrar el dinero, será este quien asuma los costos y gastos del envío del bien, ${ }^{112}$ situación que resulta lógica en el entendido que es el consumidor quien a pesar de haber otorgado su consentimiento se arrepiente, y este arrepentimiento no puede ser soportado por el productor o proveedor. Sin embargo, en la figura de la reversión la ley le otorga esta carga al consumidor de forma absoluta en todos los casos en que procede la devolución. ${ }^{113} \mathrm{~A}$ pesar de lo

110 Artículo 47 de la Ley 1480 de 2011.

111 Artículo 6 del Decreto 735 del 17 de abril de 2013.

112 Artículo 47 inciso $2^{\circ}$.

113 Artículo 51 inciso $2^{\circ}$. 
anterior, siguiendo un criterio de interpretación de las obligaciones entre las partes, propongo el esquema del cuadro 4 sobre los gastos y costos del envío del bien en el caso de reversión.

Cuadro 4. Parte que asume los costos y gastos del envío del producto en la reversión.

\begin{tabular}{|c|c|c|}
\hline Grupo & Situación & ¿Quién asume el envío? \\
\hline \multirow{2}{*}{ 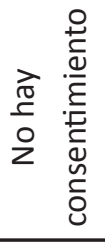 } & Fraude & No aplica \\
\hline & $\begin{array}{l}\text { Operación no } \\
\text { solicitada }\end{array}$ & Producto/proveedor \\
\hline \multirow{3}{*}{ 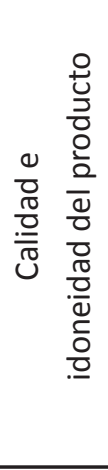 } & $\begin{array}{l}\text { El producto no } \\
\text { se ha recibido }\end{array}$ & No aplica \\
\hline & $\begin{array}{l}\text { El producto } \\
\text { entregado no } \\
\text { corresponde a } \\
\text { lo solicitado }\end{array}$ & Producto/proveedor \\
\hline & $\begin{array}{c}\text { El producto sea } \\
\text { defectuoso }\end{array}$ & Producto/proveedor \\
\hline 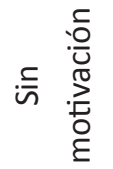 & $\begin{array}{c}\text { Sin justificación } \\
\text { en obligaciones } \\
\text { periódicas }\end{array}$ & No aplica \\
\hline
\end{tabular}

Fuente: elaboración propia.

Resulta apenas lógico que cuando la operación haya sido ocasionada por un fraude a través de medios electrónicos, el producto no haya sido entregado o se trate de una reversión por obligaciones periódicas, no haya injerencia en la devolución de un producto, puesto que, por un lado, se trata de una operación que nació sin el consentimiento del consumidor y benefició a un tercero o ciberdelincuente anónimo, además, según el artículo 50 literal f), el pro- veedor será el responsable de las fallas en la seguridad de las transacciones realizadas por los medios que él mismo dispuso, sin importar si son propios o ajenos; por otro lado, dado que el producto nunca llegó al domicilio del consumidor, no se puede efectuar su devolución. $Y$ finalmente, tratándose de reversiones de pago sobre obligaciones de cumplimiento periódico, como ya se explicó, no atienden a una resolución del contrato sino al pago sobre esa obligación, pero será satisfecha por el consumidor por otros medios.

Consecuentemente, cuando nos encontramos frente a la situación en que el producto llegó al domicilio del consumidor pero este nunca lo solicitó, el producto entregado no corresponde a lo solicitado o el producto está defectuoso, le corresponderá al productor o proveedor pagar o asumir los costos asociados a la devolución del producto. Puesto que el consumidor aduce que no dio el consentimiento para determinada operación, queda en cabeza del productor o proveedor demostrar lo contrario, y mientras no se demuestre que sí lo hizo, el consumidor no puede asumir un costo por un producto que no había solicitado. Por otro lado, dado que es responsabilidad del productor o proveedor entregar el bien que previamente ofreció con determinadas características, ${ }^{114}$ cuando el producto no posea las calidades que se habían acordado o se encuentre defectuoso será este quien asuma los gastos. Por lo tanto, resulta errada y excesiva la afirmación del legislador cuando establece que “el consumidor deberá (...) devolver el producto,

114 Artículos $2^{\circ}$ numerales $1.1,1.5,1.7 ., 5^{\circ}$ numerales $1,6,17$. 
cuando sea procedente", pues le impone una carga adicional sin que medie un criterio diferenciador entre una y otra situación. De esta forma, sin importar si el consumidor recibió un producto no solicitado o recibió un producto defectuoso o recibió un producto que no corresponde a lo que había pedido, será siempre este quien asuma el costo del envío, lo que se traduce en un desequilibrio de las cargas entre las partes, contrariando el objeto y finalidad principal del mismo Estatuto.

Cabe recordar entonces que, a pesar de que la finalidad y el objetivo principal de esta figura es la devolución íntegra del dinero cuando procedan las situaciones mencionadas, el Estatuto del Consumidor no fijó un término para dicha devolución, lo cual deja abiertas un sin número de posibilidades en las que el consumidor puede verse afectado. Por ejemplo, cuando el medio de pago no reversa la operación hasta que el proveedor o productor no lo indiquen o viceversa, genera una clara violación a los derechos de los consumidores en la medida que su queja no logra ser respondida en un tiempo prudencial. Al respecto cabe recordar que la Superintendencia de Industria y Comercio estableció que la entrega del dinero debe hacerse "en un término razonable". ${ }^{115}$ Ello evidencia un vacío legal que, sin embargo, puede ser superado por vía de analogía con la regulación sobre el derecho de retracto, en donde se fija un término máximo para devolver el dinero de treinta (30) días calendario, desde el momento en que el consumidor ejerció el derecho.

115 SUPERINTENDENCIA DE INDUSTRIA Y COMERCIO. Comunicado. Radicado 12-229355-00002-0000 del 31 de enero de 2013.
Si aplicáramos el mismo término legal de treinta (30) días calendario para los casos en los cuales procede la reversión del pago, se estarían salvaguardando los derechos del consumidor sin afectar la empresa o la economía, pues lo que se busca con esta protección es generar un ámbito de aplicación del derecho del consumo más amplio y efectivo. Resultaría absurdo mantener la devolución del dinero en un tiempo indeterminado o a discreción del proveedor, el productor o el emisor del instrumento de pago pues se estaría ocasionando un perjuicio al consumidor. Sin embargo, dado que la Superintendencia de Industria y Comercio no ha establecido un término legal para esta devolución, resulta correcto afirmar que en la medida en que esa razonabilidad afecte el poder adquisitivo de la moneda en el tiempo, se deberá traer a valor presente el precio del producto a reversar.

La inflación se caracteriza por un alza sostenida en el nivel general de los precios de los bienes y servicios de la sociedad, y tiene como efecto inmediato la disminución o deterioro del poder adquisitivo de la moneda. Debido a la desvalorización de la moneda a causa de la inflación, se ha establecido la necesidad de reconocer determinada corrección monetaria por razones de equidad para mantener el equilibrio hasta el momento de solventar una obligación. ${ }^{116}$

\section{Procedimiento}

La reversión resulta ser entonces una figura que beneficia y protege al consumidor de determina-

116 VARÓN PALOMINO, Juan Carlos. De las obligaciones de dinero. En: Derecho de las obligaciones. Bogotá, Colombia: Temis y Universidad de los Andes, 2009, p. 69-130. 
das situaciones, pero a su vez le exige cargas procesales para el efectivo cumplimiento. Así, el procedimiento podrá iniciarse: i) Con una queja ante el proveedor o productor cuando sea procedente o ii) Con una notificación al emisor del pago, en los casos en los cuales el consumidor desconozca al proveedor o productor o este no se encuentre en el territorio nacional. Esta queja o notificación debe ser presentada dentro los cinco (5) días hábiles siguientes a la fecha en que el consumidor "tuvo noticia de la operación fraudulenta o no solicitada o que debió haber recibido el producto o lo recibió defectuoso o sin que correspondiera a lo solicitado", 117 acompañada en los casos que sea procedente de la devolución del producto, en los términos que previamente se expusieron.

Presentada la reclamación o queja, el consumidor deberá notificar de esta al emisor del instrumento de pago electrónico utilizado para dicha transacción, el cual en conjunto con los demás participantes del proceso de pago procederá a efectuar la reversión. Al respecto, la Superintendencia de Industria y Comercio ha manifestado que a la notificación antes mencionada no se le debe atribuir significado formal procesal, sino que debe ser entendida como una forma de "poner en conocimiento de la justificación o motivación de la solicitud de la reversión del pago". ${ }^{118}$ A su vez, señaló que dicha notificación deberá contener los datos mínimos para que el emisor del instrumento de pago electrónico individua-

117 Artículo 51 inciso $2^{\circ}$.

118 SUPERINTENDENCIA DE INDUSTRIA Y COMERCIO. Consulta. Radicado 12-70858-3-0 del 25 de junio de 2012. lice la transacción de la que se trata y acompañarse de una copia de la queja presentada por el consumidor ante el proveedor. ${ }^{119}$ Luego de ello, todos los participantes del proceso de pago proceden a efectuar la materialización de la reversión, notificando de ello al consumidor.

Según la Asobancaria, la figura de la reversión del pago “(...) les impone a los actores que participan en el comercio electrónico, avanzar en el fortalecimiento de las herramientas requeridas para mitigar la posibilidad de efectuar compras fraudulentas o no consentidas por los clientes". ${ }^{120}$ Se pone de presente, entonces, la necesidad de crear políticas de autorregulación y adecuado manejo del e-commerce. Adoptar estos mecanismos y crear procedimientos especiales internos para el manejo de estas situaciones hará que las empresas sean cada vez más competitivas en este mercado.

Sin embargo, existe la posibilidad de que los empresarios consideren infundada la solicitud de reversión y decidan iniciar un proceso administrativo o judicial para resolver la controversia. ${ }^{121}$ El fallo deberá ser notificado al consumidor y, según la Superintendencia de Industria y Comercio, entendido como una notificación formal en los términos procesales establecidos en la legislación colombiana. ${ }^{122}$

119 Ibíd

120 CUELLAR, María Mercedes. Óp. cit. p. 8.

121 Artículo 51 inciso $3^{\circ}$ de la Ley 1480 de 2011

122 Artículos 313 y siguientes del Título XV del Código de Procedimiento Civil. Este código fue derogado por el artículo 626 de la Ley 564 de 2012, sin embargo la nueva regulación sobre notificaciones empezará 
Si el pleito se resuelve a favor del consumidor, la reversión se entenderá como definitiva, pero si se resuelve a favor del proveedor o productor, el emisor del instrumento de pago: 1) Si es posible, cargará o debitará la transacción reclamada al depósito bancario o instrumento de pago correspondiente de la cuenta del consumidor, y el dinero será puesto a disposición del proveedor o productor. 2) Si no es posible, por no existir fondos suficientes o por cualquier otro motivo, los participantes en el proceso de pago informarán al proveedor para que este inicie las acciones que considere pertinentes contra el consumidor. Con este mecanismo se busca salvaguardar los intereses y derechos del empresario, pues a pesar de que la reversión resulta ser un instrumento muy favorable para el consumidor, puede ser utilizado para generar perjuicios en contra del empresario.

Debido a ello, el Estatuto del Consumidor previó la posibilidad de que la reversión pueda ser utilizada de mala fe por parte del consumidor, para consumir o usar bienes o servicios y luego alegar una de las situaciones que le permiten revertir el pago. De ser este el caso, si el empresario logra demostrar la mala fe del consumidor, la Superintendencia podrá imponerle una sanción de hasta cincuenta (50) salarios mínimos legales mensuales vigentes, ${ }^{123}$ sin perjuicio del cobro coactivo de la obligación.

El anterior procedimiento se surte sin perjuicio de los mecanismos de protección que se recla-

a regir a partir del $1^{\circ}$ de enero de 2014 . La nueva reglamentación se encuentra en la sección cuarta, título II de la nueva ley.

123

Artículo 51 inciso $4^{\circ}$. man ante la Superintendencia Financiera, cuando se trate de operaciones fraudulentas o no solicitadas que impliquen una violación a la seguridad de los datos de los consumidores, en el contexto del comercio electrónico, y en los cuales el emisor del instrumento de pago se niegue a la reversión. En este caso el proceso se inicia con la presentación de la queja ${ }^{124}$ por parte del consumidor ante el emisor del instrumento de pago -que es vigilado por la Superintendencia Financiera- quien la tramita, y si cumple los requisitos le da traslado a la entidad correspondiente, dentro de los 15 días hábiles siguientes a la presentación de la queja. En este punto, si la entidad lo considera necesario, podrá solicitar información adicional al consumidor. Luego de ello, la Superintendencia Financiera evalúa la información, así como la solución, aclaración o explicación que haya recibido la queja y da respuesta en ese sentido. Sin embargo, si considera que la entidad vigilada ha violado alguna disposición, inicia en forma independiente una actuación administrativa tendiente a establecer si se configura o no una infracción. ${ }^{125}$

El procedimiento busca ser lo más expedito y ágil posible para evitar perjuicios al consumidor. En el cuadro 5 se presenta el flujograma de dicho proceso.

124 Los datos mínimos que debe contener la queja son: nombres y apellidos completos, número de identificación, dirección, ciudad, teléfono y la descripción de los hechos que originan el reclamo.

Para mayor información acerca del trámite ante la Superintendencia Financiera, consultar la Guía para tramitar una queja ante la Superintendencia Financiera. Disponible en: http://www.superfinanciera.gov. co/Quejas/quejasgeneral.htm. Consultado el 3 de mayo de 2013. 
Cuadro 5. Flujograma del proceso de reversión

del pago

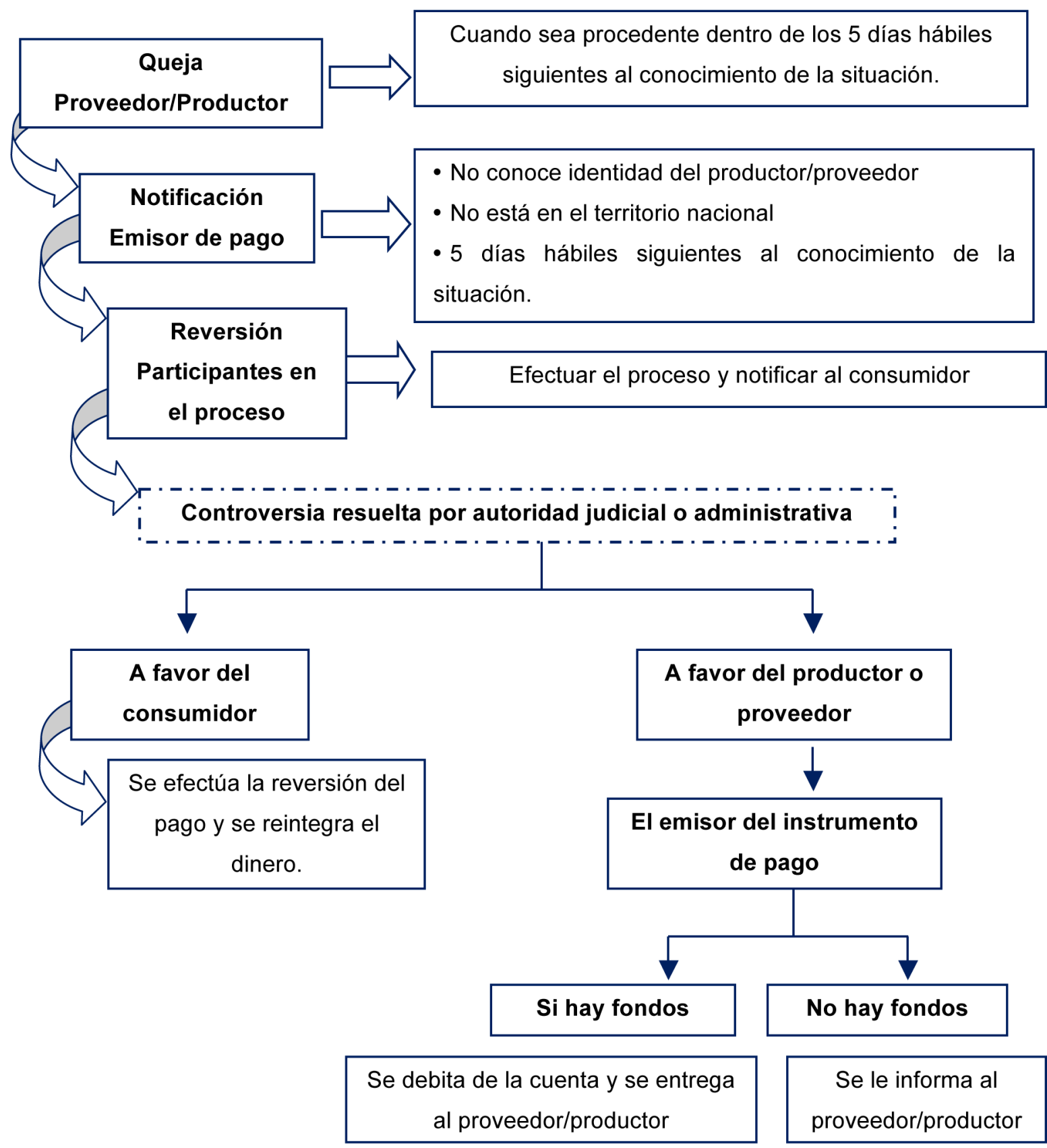

Fuente: elaboración propia. 
La reversión se convierte, entre otras, en un mecanismo efectivo de protección del consumidor frente a prácticas fraudulentas transfronterizas, porque quienes le responderán serán los emisores del instrumento de pago. Así por ejemplo, si a la tarjeta de crédito Visa de un ciudadano colombiano se le cargan $\$ 5.000 .000$ por una supuesta compra que realizó vía página web de un empresario chino, el afectado reclama ante Visa, quien deberá devolverle el dinero, sin que tenga que iniciar ningún proceso ante las autoridades de protección del consumidor de la China.

Dentro de la investigación de campo que se realizó en varias empresas, solo Avianca ${ }^{126}$ precisó la forma como maneja internamente la figura de la reversión. Avianca usa la plataforma compras en línea para que sus clientes adquieran el tiquete de vuelo que les permite utilizar sus servicios. En relación con los casos de reversión del pago explicó:

[E]n operaciones fraudulentas es necesario que el cliente se dirija a su banco y presente la reclamación por la compra que desconoce, y el banco procede a validar con el comercio la veracidad de la compra. Esta información es recepcionada en el correo GENCERTIFBANCOS@ avianca.com donde se radican todos los casos y estos deben ser analizado[s] y verificados para dar respuesta a las entidades financieras, con el fin de demostrar al cliente la compra y en caso que siga siendo rechazada por el cliente [,] el banco procede a debitarnos la transacción y el valor será reintegrado al tarjetahabiente.

126 Dentro de las empresas a las cuales se les solicitó la información acerca del procedimiento para efectuar la reversión están: LAN, Falabella, Alkosto y Avianca. Solo Avianca contestó al derecho de petición y suministro de información relevante.
Mientras, el comercio recurre al bloqueo del tiquete para evitar su utilización.

Como se ve, (I) entre el emisor del instrumento de pago y el proveedor o productor (Avianca) existe comunicación en lo relacionado con la validación de la información, que resulta de gran importancia para evitar cargas excesivas al consumidor y que sea este quien informe a una y otra parte; (II) la compañía solo inicia el trámite de la reversión cuando ha sido informada por el medio de pago, lo cual va en contravía de la ley, pues esta ordena que el consumidor deberá poner en conocimiento de la situación tanto al proveedor como al medio de pago, para que cada uno adopte las medidas pertinentes. En este caso, si el proveedor o productor espera a que el medio de pago le informe sobre la reversión, es probable que el tiquete solicitado en forma fraudulenta alcance a ser usado. En prevención, el proveedor o productor podría poner a disposición del cliente medidas temporales de bloqueo.

También como parte de la investigación se solicitó información a diferentes entidades bancarias, ${ }^{127}$ sobre el procedimiento de reversión del pago, sanciones al cuentahabiente y tiempo aproximado de esta operación. Sin embargo, pasados aproximadamente tres meses ninguna dio respuesta a pesar de haber presentado la solicitud como derecho de petición. La negativa lleva a pensar en un posible desinterés de la banca y sus políticas internas frente a la atención al cliente y a los instrumentos de pago

127 Se enviaron derechos de petición a entidades como Davivienda, Banco de Bogotá, Bancolombia y CityBank. 
electrónico para salvaguardar los derechos de los consumidores.

\section{Términos y condiciones: casos prácticos}

Cuando el consumidor decide realizar una compra a través del comercio electrónico debe aceptar las políticas empresariales de cada productor o proveedor, que por lo general puede leer en línea. Sin embargo, dichos términos y condiciones muy pocas veces son leídos con la atención debida por el consumidor, exponiéndose al desconocimiento de sus derechos y obligaciones y, finalmente, a disputas entre las partes. Dentro de los deberes del consumidor ${ }^{128}$ se encuentra el informarse sobre la calidad del producto y las instrucciones de uso o de consumo, para lo cual deberá leer los términos y condiciones que el productor o proveedor ponen a su disposición, así como las condiciones bajo las cuales está realizando la transacción.

Sin ánimo de realizar un análisis sobre la interpretación de los contratos en masa o en línea, es importante aclarar que dentro de este esquema la mayoría de los empresarios utilizan los llamados contratos por adhesión, que implican una posición de dominio frente al consumidor en razón de que le otorgan al proveedor o productor: 1) El privilegio de predisponer unilateralmente el clausulado del contrato y 2) Administrar el contrato durante toda la relación contractual. ${ }^{129}$ El reconocimiento de los instrumentos

128 Artículo 3 numeral 2 de la Ley 1480 de 2011.

129 ARRUBLA PAUCAR, Jaime Alberto. La posición dominante en los contratos, el abuso de la misma y la protección del adherente en el para contratación masiva es la solución para las transacciones en el mercado globalizado, de ahí que se haya llegado a aceptar que la posición de dominio en este tipo de contratos no va en contravía de los derechos de los consumidores. Lo erróneo sería el abuso de esa posición, por ejemplo, con la inserción de cláusulas que coloquen al empresario en una situación de privilegio frente al adherente con el objeto de sacar ventaja. ${ }^{130}$ Esta posición dominante del empresario en cuanto a la predisposición del contrato, no implica que pueda estipular cláusulas que violen derechos de los consumidores.

En el cuadro 6 se referencian algunos sitios web de empresas que venden sus productos a través del comercio electrónico y su política sobre reversión del pago, devoluciones o responsabilidades por fallas en el sitio web. Este ejercicio muestra también algunas confusiones y aciertos en que incurren los empresarios. ${ }^{131}$

sistema colombiano. Perspectivas del derecho de consumo. Bogotá: Universidad Externado de Colombia, 2013, p. 230.

130 Ibíd., p. 240.

131 Las empresas fueron escogidas al azar por ser las más concurridas por la autora al momento de realizar compras a través del comercio electrónico. 


\section{Cuadro 6. Términos y condiciones de empresas en relación con la reversión}

\begin{tabular}{|c|c|}
\hline Empresa & Términos y condiciones relacionados con la reversión \\
\hline Dafiti & $\begin{array}{l}\text { "Improcedencia del Derecho de Retracto: Dafiti comercializa bienes de uso personal y } \\
\text { por tanto, de acuerdo a la normativa vigente, no se podrá ejercer el derecho de retracto } \\
\text { en ninguna circunstancia. Así declara conocerlo y aceptarlo el Cliente al aceptar los pre- } \\
\text { sentes términos y condiciones. Lo anterior, sin perjuicio de la posibilidad de cambios que } \\
\text { voluntariamente otorga Dafiti a sus Clientes respecto de aquellos productos que Dafiti } \\
\text { expresamente indique". }{ }^{132}\end{array}$ \\
\hline Mercado Libre & $\begin{array}{l}\text { "La oferta de compra es irrevocable salvo en circunstancias excepcionales, tales como } \\
\text { que el vendedor cambie sustancialmente la descripción del artículo después de real- } \\
\text { izada alguna oferta, que exista un claro error tipográfico, o que no pueda verificar la } \\
\text { identidad del vendedor." } \\
\text { "Mercado Libre no se responsabiliza por cualquier daño, perjuicio o pérdida al Usuario } \\
\text { causados por fallas en el sistema, en el servidor o en Internet". }{ }^{133}\end{array}$ \\
\hline Falabella & $\begin{array}{l}\text { "Si el cliente quiere anular una compra, puede hacerlo a través del Call Center, pero si } \\
\text { el producto ya fue enviado por FALABELLA a la dirección indicada por el Cliente, éste } \\
\text { deberá pagar el costo del retiro, que tiene la misma tarifa del envío." } \\
\text { "Para realizar un cambio o una devolución, acércate con tu factura y el producto, a cu- } \\
\text { alquiera de nuestras tiendas, o recibe asistencia llamando a Servicio al Cliente en Bogotá } \\
5878002 \text { o a nivel nacional al } 018000113252 . " \\
\text { "Falabella no realiza devolución de dinero"134 }\end{array}$ \\
\hline Homecenter & $\begin{array}{l}\text { “Los usuarios de www.homecenter.com.co gozan de la posibilidad de ejercer su derecho } \\
\text { al retracto de su compra; es decir, pueden de manera autónoma y libre solicitar que se } \\
\text { reverse la compra volviendo las cosas a su estado inicial; esto es, por parte del usuario } \\
\text { reintegrando la mercancía adquirida en perfectas condiciones, sin haberla usado y apta } \\
\text { para una nueva venta y por parte de SODIMAC COLOMBIA S. A. -Almacenes Homecen- } \\
\text { ter- efectuando la devolución de lo pagado por el producto. Siempre que cumpla con } \\
\text { las siguientes condiciones: } \\
\text { - Oportunidad: Dentro de los cinco (5) días siguientes a la entrega del producto. }\end{array}$ \\
\hline
\end{tabular}

132 Términos y condiciones Dafiti.com. Disponibles en: http://www.dafiti. com.co/terminos-y-condiciones/ Consultado el 3 de mayo de 2013

133 Términos y condiciones Mercadolibre.com. Disponibles en: http://ayuda.mercadolibre.com.co/seguro_terminos. Consultado el 3 de mayo de 2013.

134 Términos y condiciones Falabella.com. Disponibles en: http://www. falabella.com.co/falabella-co/category/cat111251/Terminos-y-condiciones. Consultado el día 3 de mayo de 2013. 


\begin{tabular}{|c|c|}
\hline Empresa & Términos y condiciones relacionados con la reversión \\
\hline Homecenter & $\begin{array}{l}\text { Estado de la mercancía: El usuario deberá devolver el producto a SODIMAC CO- } \\
\text { LOMBIA S. A., en las mismas condiciones que lo recibió, sin haber usado el artículo, } \\
\text { en su caja o empaque original, en perfecto estado, apto para una nueva venta y con } \\
\text { sus piezas completas. } \\
\text { - Costos de transporte: Deberán ser asumidos por el usuario y los demás que conl- } \\
\text { leven la devolución del bien. } \\
\text { - Productos excluidos: El derecho de retracto no aplicará para productos sobre pe- } \\
\text { dido o aquellos que fueron elaborados, fabricados, armados, cortados o preparados } \\
\text { conforme a las especificaciones del usuario o que son claramente personalizados. } \\
\text { SODIMAC colOMBIA S. A. -Almacenes Homecenter- efectuará la devolución del dinero al } \\
\text { usuario, dentro de los treinta (30) días calendario siguientes a la recepción de la mercancía } \\
\text { devuelta. La mercancía podrá ser devuelta a través de estos medios a elección del usuario: } \\
\text { - Entregándola personalmente en el almacén Homecenter de la ciudad a donde se } \\
\text { despachó el pedido. } \\
\text { - Llamando a la línea: } 3077115 \text { opción } 1 \text { donde se coordinará la recogida en su domi- } \\
\text { cilio a través de una empresa transportadora de mercancía. Le recordamos que quien } \\
\text { ejerza el derecho de retracto deberá pagar el valor de éste servicio". }{ }^{135}\end{array}$ \\
\hline Éxito & $\begin{array}{l}\text { "En caso de que un producto no esté disponible podrá cambiarse por un sustituto o una } \\
\text { tarjeta regalo correspondiente al valor del mismo. En ningún caso exito.com realizará re- } \\
\text { versiones parciales, todas deben realizarse por el valor total pagado en la respectiva trans- } \\
\text { acción". }{ }^{136}\end{array}$ \\
\hline
\end{tabular}

Fuente: elaboración propia.

De la anterior muestra se pueden sacar las siguientes conclusiones sobre las empresas que venden en línea: 1) aún no cuentan con una política sobre reversión del pago en los casos que expresamente señala la ley. 2) tienden a confundir la reversión del pago con el derecho de retracto y, por tanto, sin importar las circunstancias, el consumidor siempre deberá asumir los costos del envío del bien. 3) algunas no devuelven el dinero; le entregan al consumidor una tarjeta regalo que podrá redimir en el mis-

135 Términos y condiciones Homecenter.com. Disponibles en: http://portal. homecenter.com.co/terminosycondiciones\#tiempos. Consultado el día 3 de mayo de 2013.

136 Términos y condiciones éxito.com. Disponibles en: http://www.exito. com/about/content.jsp?id=terminos. Consultado el 13 de mayo de 2013. mo establecimiento en un tiempo determinado, lo cual va en contravía de los derechos de los consumidores.

El Estatuto del Consumidor estableció dos figuras con efectos y situaciones diferentes: la reversión del pago en las condiciones que se señalaron previamente, y el derecho de retracto que procede en ciertas circunstancias. En el cuadro 7 se señalan las diferencias entre las dos figuras: 137

137 Información tomada de REMOLINA ANGARITA, Nelson y FLÓREZ ROJAS, María Lorena. Consumidor y comercio electrónico. En: J. M. Gual Acosta y J. C. Villalba Cuéllar. Derecho del Consumo: Problemáticas Actuales. Bogotá, Colombia: Ibañez y Universidad Santo Tomás, 2013, p. 350-364. 
Cuadro 7. Diferencias entre reversión del pago y derecho de retracto

\begin{tabular}{|c|c|c|}
\hline Factor & Derecho de retracto & Reversión del pago \\
\hline Nombre & Retracto (art. 47) & Reversión del pago (art. 51) \\
\hline $\begin{array}{l}\text { Medios de } \\
\text { pago }\end{array}$ & $\begin{array}{l}\text { Sistema de financiación otorgada por el } \\
\text { productor o proveedor. }{ }^{138}\end{array}$ & $\begin{array}{l}\text { Uso de tarjeta de crédito, débito o cualquier otro instrumen- } \\
\text { to de pago electrónico. }\end{array}$ \\
\hline $\begin{array}{l}\text { Casos en los } \\
\text { que procede }\end{array}$ & $\begin{array}{l}\text { Venta de bienes y prestación de servicios } \\
\text { Venta de tiempos compartidos. }{ }^{139} \\
\text { Ventas que utilizan métodos no tradiciona- } \\
\text { les }{ }^{140} \text { o a distancia. }{ }^{141}\end{array}$ & $\begin{array}{l}\text { Ventas de bienes mediante mecanismos de comercio elec- } \\
\text { trónico como Internet, PSE, call center, televenta o tienda } \\
\text { virtual. } \\
\text { Cuando sea objeto de: } \\
\text { - Fraude } \\
\text { - Operación no solicitada } \\
\text { - El producto adquirido no se reciba. } \\
\text { - El producto entregado no corresponda a lo solicitado } \\
\text { - El producto sea defectuoso }\end{array}$ \\
\hline Excepciones & $\begin{array}{l}\text { - Prestación de servicios que haya } \\
\text { comenzado con el acuerdo del con- } \\
\text { sumidor } \\
\text { - Bienes o servicios cuyo precio esté } \\
\text { sujeto a fluctuaciones del mercado } \\
\text { financiero que el productor no pu- } \\
\text { eda controlar. } \\
\text { - Bienes confeccionados conforme a } \\
\text { - } \text { las especificaciones del consumidor. } \\
\text { puedan qer devueltos o puedan de- } \\
\text { teriorarse o caducar con rapidez. } \\
\text { - Servicios de apuestas y loterías. } \\
\text { - Adquisición de bienes perecederos. } \\
\text { - Adquisición de bienes de uso per- } \\
\text { sonal. }\end{array}$ & $\begin{array}{l}\text { El consumidor tendrá derecho a reversar los pagos cor- } \\
\text { respondientes a cualquier servicio u obligación de } \\
\text { cumplimiento periódico, por cualquier motivo y aún sin } \\
\text { que medie justificación alguna, siempre que el pago se } \\
\text { haya realizado a través de una operación de débito au- } \\
\text { tomático autorizada previamente por dicho consumidor, } \\
\text { en los términos que señale el Gobierno Nacional para el } \\
\text { efecto. }\end{array}$ \\
\hline
\end{tabular}

Elaborado por: Nelson Remolina Angarita y Maria Lorena Flórez Rojas.

138 Adicionado en la Ponencia para Primer Debate. Gaceta del Congreso n. ${ }^{\circ} 352$ del $1^{\circ}$ de junio de 2011.

139 Sistema de acceso a los servicios hoteleros en el cual se presenta el fraccionamiento de los derechos de uso de un complejo turístico en tantas semanas como tiene el año, con el fin de ofrecer cada una de ellas a los posibles clientes, los cuales adquieren el derecho de alojarse durante su respectiva semana o semanas adquiridas, por un número variable de años.
140 Artículo 5 numeral 15 de la Ley 1480 de 2011: son aquellas que se celebran sin que el consumidor las haya buscado, tales como las que se hacen en el lugar de residencia del consumidor o por fuera del establecimiento de comercio. Se entenderá por tales, entre otras, las ofertas realizadas y aceptadas personalmente en el lugar de residencia del consumidor, en las que el consumidor es abordado por quien le ofrece los productos de forma intempestiva por fuera del establecimiento de comercio o es llevado a escenarios dispuestos especialmente para aminorar su capacidad de discernimiento.

141 Artículo 5 numeral 16 de la Ley 1480 de 2011: Son las realizadas sin que el consumidor tenga contacto directo con el producto que adquiere, que se dan por medios tales como correo, teléfono, catálogo o vía comercio electrónico. 
De lo anterior se desprende que el consumidor, en el contexto del comercio electrónico, tiene derecho a reversar los pagos, a retractarse de las compras en las que sea procedente y, adicionalmente, a iniciar los procedimientos concernientes ante la Superintendencia de Industria y Comercio o ante la Superintendencia Financiera, según proceda.

\section{CONCLUSIONES}

La creciente y acelerada globalización ha llevado a los consumidores a satisfacer sus necesidades de consumo en un nuevo contexto: el comercio electrónico. Este mercado en línea para la adquisición de bienes y servicios trae consigo ventajas y riesgos para las partes, igual como sucede en las adquisiciones tradicionales (offline). Sin embargo, debido a las características especiales bajo las cuales se contrata en el comercio electrónico, los consumidores debemos educarnos para conocer cómo opera, evitar riesgos en la internet y exigir que sean garantizados nuestros derechos. De igual forma, el empresario, como parte que redacta el contrato, debe garantizar el goce efectivo de los derechos del consumidor, a través de cláusulas que bajo ninguna circunstancia impliquen abuso de su posición de dominio.

Uno de los derechos que le otorgó el legislador al consumidor, como novedad frente al anterior régimen, es la reversión del pago. En esta figura intervienen el productor o proveedor, el emisor del pago y el consumidor. Su objeto es permitir al consumidor retrotraer el pago que efectúo sobre un producto, cuando se presente alguna de las siguientes hipótesis: fraude, operación no solicitada, producto defectuoso, producto que no corresponde a lo solicitado y producto no recibido. En cualquiera de las anteriores circunstancias tanto el productor como el proveedor deberán reversar la transacción y devolver al consumidor la totalidad del dinero. Sin embargo, la reversión del pago necesita todavía desarrollarse no solo en materia legislativa sino en sede de empresa, pues persisten grandes vacíos y en muchos casos puede llegar a confundirse con otras figuras como el derecho de retracto. Por ello, a pesar de la regulación vigente, todavía existe la necesidad de una reglamentación clara en relación con: 1) la devolución del dinero, en cuanto a su integridad y temporalidad; 2) la asunción de gastos y costos de devolución del producto; y 3) las medidas preventivas que se pueden adoptar en sede de empresa.

Aún así, la reversión del pago es un mecanismo efectivo de protección del consumidor frente a prácticas fraudulentas, especialmente las transfronterizas. La efectividad de esta figura en la situación planteada puede convertirla en una buena práctica regulatoria a replicar en otros países.

\section{Bibliografía}

Arbeláez, M. A. y Zuluaga, Sandra. (2006). Medios de pago electrónicos en Colombia: evolución y perspectivas. Recuperado de http:// www.minhacienda.gov.co/portal/page/portal/HomeMinhacienda/regulacionfinancie- 
ra/Presentaciones/Presentaciones/9_9.+S ISTEMAS+ELECTRONICOS+DE+PAGO+EN+C OLOMBIA.pdf.

Arrubla Paucar, J. A. (2013). La posición dominante en los contratos, el abuso de la misma y la protección del adherente en el sistema colombiano. En Perspectivas del derecho de consumo. Bogotá: Universidad Externado de Colombia.

Betancur, B. (1998). Filosofía de los derechos humanos. En Política y derecho del consumo. Bogotá: Superintendencia de Industria y Comercio. Biblioteca Milenio.

Burgos Puyo, A. (2007). El consumidor y los contratos en internet. Bogotá, Colombia: Universidad Externado de Colombia.

Calais-Auloy, J. (2010). Droit de la Consommation. ( $8^{\mathrm{a}}$ ed.). Paris, Francia: Dalloz.

Chaves Alvarado, D. A. (2006). Perfil del internauta colombiano y metodología para e-business B2C en Colombia. [Tesis de Pregrado]. Universidad de los Andes, Bogotá, Colombia.

Consejo de Estado. Sala de lo Contencioso Administrativo. Sección Primera. Sentencia del 24 de septiembre de 1998. Referencia. Expediente: 5014. Consejero ponente: Juan Alberto Polo Figueroa.

Consejo de Estado. Sala de lo Contencioso Administrativo. Sección Primera. Sentencia del 8 de mayo de 2003. Referencia. Expediente: 25000-23-24-000-2001-0849-01(8149).
Consejero ponente: Manuel Santiago Urueta Ayola.

Contreras S., J. (2012). Estudio de comercio electrónico en América Latina. Recuperado de http://www.ecommerceday.co/2012/ wp-content/uploads/2012/08/eCommerceStudy-Part-I-Visa-America-Economia-2012ESP.pdf.

Corporación Colombia Digital. (2012). Estadísticas de uso de Internet en Colombia. Recuperado de http://www.colombiadigital. net/entorno-tic/noticias/tic-en-colombia/ item/4087-estad\%C3\%ADsticas-de-uso-deinternet-en-colombia.html.

Corte Constitucional. C-1141 de agosto 30 de 2000. Referencia: expediente D-2830. Magistrado ponente: Eduardo Cifuentes Muñoz.

Corte Constitucional. T-118 de 2000. Referencia. Expediente: T-250298. Magistrado ponente: José Gregorio Hernández Galindo.

Corte Constitucional. T-333 de 2000. Referencia. Expediente: T-267601. Magistrado ponente: Eduardo Cifuentes Muñoz.

Corte Constitucional. C-973 de 2002. Referencia. Expediente: D-4032. Magistrado ponente: Álvaro Tafur Galvis.

Corte Constitucional. T-747 de 2002. Referencia. Expediente: T-599615. Magistrado ponente: Marco Gerardo Monroy Cabra. 
Corte Constitucional. T-145 de 2004. Referencia. Expediente: T-730843. Magistrado ponente: Álvaro Táfur Galvis.

Corte Constitucional. C-749 de 2009. Referencia: expediente D-7686. Magistrado ponente: Luis Ernesto Vargas Silva.

Corte Suprema de Justicia. Sala Plena. Sentencia 107 de 1986. Referencia. Expediente: 1496. Magistrado ponente: Hernando Gómez Otálora.

Corte Suprema de Justicia. Sala de Casación Civil. Sentencia del 13 de diciembre de 2001. Referencia. Expediente: 6775. Magistrado ponente: Manuel Ardila Velásquez.

Corte Suprema de Justicia. Sala de Casación Civil. Sentencia del 3 de mayo de 2005. Ref.: Expediente. No. 500013103001199904421-01. Magistrado ponente: César Julio Valencia Copete.

Cuellar, M. M. (2011). Discurso de Instalación V Congreso de Prevención del Fraude y Seguridad. Recuperado de http:// www.asobancaria.com/portal/pls/portal/ docs/1/1844048.PDF.

Escajedo San Epifanio, L. (2007). La base jurídico-constitucional de la protección de los consumidores en la Unión Europea. Revista de Derecho Político.

Ghersi, C. A. (1998). La concepción filosófica del derecho del consumo y su relación con otras disciplinas. En Política y derecho del consu- mo. Bogotá, Colombia: Superintendencia de Industria y Comercio. Biblioteca Milenio.

Giraldo López, A., Caycedo Espinel, C. G. y Ramón, M. R. (2012). Comentarios al nuevo Estatuto del Consumidor. Bogotá D. C.: Legis.

Grupo de Estudios en Internet, Comercio Electrónico, Telecomunicaciones e Informática. (2002). Internet, Comercio Electrónico \& Telecomunicaciones. Bogotá, Colombia: Legis y Universidad de los Andes.

Hinestrosa Forero, F. (2007). Tratado de las Obligaciones. 3ra. ed. Bogotá, Colombia: Universidad Externado de Colombia.

Hocsman, H. (2005). Negocios en Internet. Buenos Aires, Argentina: Astrea.

International Telecommunication Union. (2013). The World in 2013: ICT Facts and Figures. Recuperado de http://www.itu.int/en/ITUD/Statistics/Documents/facts/ICTFactsFigures2013.pdf.

Laguado Giraldo, R. (2006). Estudios jurídicos sobre comercio electrónico. Bogotá, Colombia: Cámara de Comercio de Bogotá y Pontificia Universidad Javeriana.

Lorenzetti, R. L. (2003). Consumidores. Buenos Aires, Argentina: Rubinzal-Culzoni.

Matute, G., et al. (2012). Del consumidor convencional al consumidor digital: el caso de las tiendas por departamento. Lima, Perú: Universidad ESAN. 
Montaqim, A. (2012). Global e-commerce sales sales will top $\$ 1,25$ trillon by 2013 . Recuperado de http://www.internetretailer. com/2012/06/14/global-e-commerce-sales-will-top-125-trillion-2013. Consultado el día 15 de mayo de 2013.

Plata López, L. C. (2013). La protección a los consumidores en el comercio electrónico. En Derecho del consumo: problemáticas actuales. Bogotá, Colombia: Grupo Editorial Ibañez y Universidad Santo Tomás.

Remolina Angarita, N. (2002). Desmaterialización, documento electrónico y centrales de riesgo. En Internet, Comercio Electrónico \& Telecomunicaciones. Bogotá D.C.: Grupo de Estudios en Internet, Comercio Electrónico \& Telecomunicaciones e Informática (GECTI).

Remolina Angarita, N. y Flórez Rojas, M. L. Consumidor y comercio electrónico. En: Derecho del consumo: problemáticas actuales. Bogotá, Colombia: Ibañez y Universidad Santo Tomás.

Rico Carrillo, M. (2012). El pago electrónico en internet: estructura operativa y régimen jurídico. España: Aranzadi.

Rob, P. C. (2003). Sistemas de bases de datos: diseño, implementación y administración. (3a. ed.). México D. F.: Cengage Learning.

Ruscono, D. (2013). La noción del consumidor en la ley 1480 de 2011. En Derecho del consumo: problemáticas actuales. Bogotá, Colombia: Universidad Santo Tomás y Grupo Editorial Ibañez.

Santa María, P. C. (2006). Quejas: indicador de calidad del servicio bancario. La Semana Económica.

Superintendencia de Industria y Comercio. Concepto No. 960272 del 2 de septiembre de 1996.

Superintendencia de Industria y Comercio. Concepto No. 96060904 del 28 de noviembre de 1996.

Superintendencia de Industria y Comercio. Concepto No. 97023655 del 17 de julio de 1997.

Superintendencia de Industria y Comercio. Concepto No. 15125 del 23 de mayo de 2000.

Superintendencia de Industria y Comercio. Concepto No. 010668522 del 28 de agosto de 2001.

Superintendencia de Industria y Comercio. Consulta Radicado 12-70858-3-0 del 25 de junio de 2012.

Superintendencia de Industria y Comercio. Comunicado Radicado No. 12-229355-000020000 del 31 de enero de 2013.

Superintendencia Financiera. Concepto No. 2008081133 del 9 de febrero del 2009 
Superintendencia Financiera. Concepto No. 2011054054-002 del 6 de septiembre de 2011.

Superintendencia Financiera. Concepto 2012021788-002 del 27 de marzo de 2012

Superintendencia Financiera. Concepto No. 2011062919-001 del 6 de septiembre de 2011.

Superintendencia Financiera. Fallo del expediente: 2012-0020, Radicado interno: 201250156.

Superintendencia Financiera. Fallo del expediente: 2012-0051. Radicado interno: 2012070946.

Superintendencia Financiera. Fallo del expediente: 2012-0061, Radicado interno: 2012073104.
Symantec. (2012). Symantec Internet Secuirty Thretat. 18 vol. Recuperado de http:// www.symantec.com/content/en/us/enterprise/other_resources/b-istr_main_report_ v18_2012_21291018.en-us.pdf.

Tambussi, C. E. (2009). El consumo como derecho humano. Buenos Aires, Argentina: Universidad.

Varón Palomino, J. C. (2009). De las obligaciones de dinero. En Derecho de las Obligaciones. Tomo I). Bogotá, Colombia: Temis y Universidad de los Andes.

Velandia, M. (2011). Derecho de la competencia y del consumo. (2da. ed.). Bogotá, Colombia: Universidad Externado de Colombia. 